\title{
An Investigation of Retrieval Cues as a Method to Improve Eyewitness
}

\section{Identification Accuracy of Multiple Perpetrators}

\author{
by
}

Julie L. Dempsey

\begin{abstract}
A thesis submitted to the Faculty of Graduate and Postdoctoral Affairs in partial fulfillment of the requirements for the degree of

Doctor of Philosophy

in

Psychology

Carleton University

Ottawa, Ontario
\end{abstract}

(C) 2012 Julie L. Dempsey 
Library and Archives

Canada

Published Heritage

Branch

395 Wellington Street

Ottawa ON K1A ON4

Canada
Bibliothèque et

Archives Canada

Direction du

Patrimoine de l'édition

395 , rue Wellington

Ottawa ON K1A ON4

Canada
Your file Votre référence

ISBN: 978-0-494-89333-3

Our file Notre référence

ISBN: 978-0-494-89333-3

\section{NOTICE:}

The author has granted a nonexclusive license allowing Library and Archives Canada to reproduce, publish, archive, preserve, conserve, communicate to the public by telecommunication or on the Internet, loan, distrbute and sell theses worldwide, for commercial or noncommercial purposes, in microform, paper, electronic and/or any other formats.

The author retains copyright ownership and moral rights in this thesis. Neither the thesis nor substantial extracts from it may be printed or otherwise reproduced without the author's permission.
AVIS:

L'auteur a accordé une licence non exclusive permettant à la Bibliothèque et Archives Canada de reproduire, publier, archiver, sauvegarder, conserver, transmettre au public par télécommunication ou par l'Internet, prêter, distribuer et vendre des thèses partout dans le monde, à des fins commerciales ou autres, sur support microforme, papier, électronique et/ou autres formats.

L'auteur conserve la propriété du droit d'auteur et des droits moraux qui protege cette thèse. $\mathrm{Ni}$ la thèse ni des extraits substantiels de celle-ci ne doivent être imprimés ou autrement reproduits sans son autorisation.
In compliance with the Canadian Privacy Act some supporting forms may have been removed from this thesis.

While these forms may be included in the document page count, their removal does not represent any loss of content from the thesis.
Conformément à la loi canadienne sur la protection de la vie privée, quelques formulaires secondaires ont été enlevés de cette thèse.

Bien que ces formulaires aient inclus dans la pagination, il n'y aura aucun contenu manquant. 


\begin{abstract}
The purpose of this research was to investigate the use of a retrieval cue as a way to facilitate recognition of a perpetrator involved in a multiple perpetrator crime. The retrieval cue in this research was a photo of one of the perpetrators involved in a twoperpetrator crime. Study 1 examined the effect of a visual image (i.e., a photo) as an effective retrieval cue for identification accuracy. After viewing a mock crime, participants $(n=189)$ were shown either an accurate cue, an inaccurate cue, or no cue prior to completing the lineup task. Results from this study indicated that witnesses presented with an inaccurate cue had lower correct identification rates compared to witnesses presented with an accurate cue or no cue. However, there was no difference in correct rejection rates. There also was no difference in accuracy rates between witnesses shown an accurate cue or no cue. Study 2 examined the influence of instruction bias and retrieval cue on identification accuracy. The retrieval cue instructions provided in Study 1 could be considered biased instructions given the instructions imply that the person in custody (i.e., the photo cue) is guilty and therefore the instructions may act as an additional retrieval cue. Participants $(n=319)$ were shown either an accurate cue, an inaccurate cue, or no cue with either biased or neutral instructions accompanying the cue. Results from Study 2 indicated a trend, suggesting that neutral instructions may help to nullify the detrimental effect of presenting an inaccurate cue to a witness. In sum, the results from the present two studies do not provide support for the use of retrieval cues as a method for improving identification accuracy of multiple perpetrators. Implications of these findings as well as limitations and future directions are discussed.
\end{abstract}




\section{Acknowledgements}

First, I would like to thank my advisor, Dr. Joanna Pozzulo, for her guidance, patience, and support. I am so fortunate to have had you as a mentor. As I start my academic career I aspire to be like you. For everything you have ever done for me I thank you. I could never have done this without you and I will always treasure my time at Carleton because of you. My appreciation also to my committee members, Dr. Craig Bennell and Dr. Shelley Brown, for all of their suggestions and insight throughout this project. Thank you to Etelle for all of your help and encouragement. I would also like to thank all of my friends at Carleton, especially Julie and Jenn - I couldn't have done this without you.

I would also like to thank my family, both old and new, for their constant support. I would especially like to thank my Dad for his unwavering support and encouragement. He was always there to listen and he always managed to make me feel better. Thank you to my Mom. You inspire me everyday and you are always with me. Thank you also to Janet and Carter for always making me smile. Thank you all so much for everything, without all of you I would never have been able to make it this far.

I would also like to extend a special thank you to Ryan. Words cannot express how much I appreciate everything you do. Without your patience, encouragement, and understanding none of this would be possible. 


\section{Table of Contents}

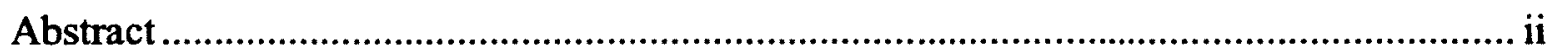

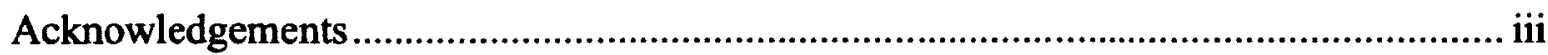

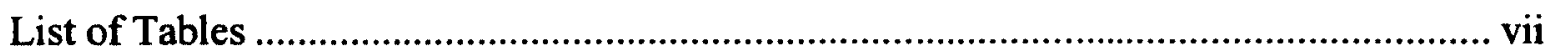

List of Appendicies .............................................................................................. viii

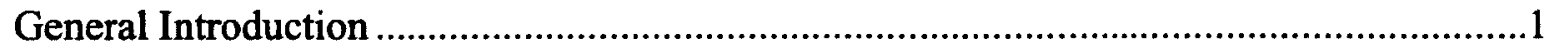

Memory

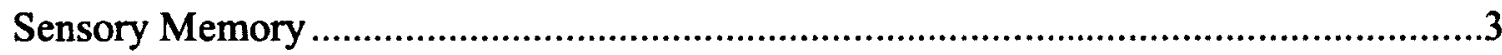

Short-Term Memory/Working Memory ……………................................................

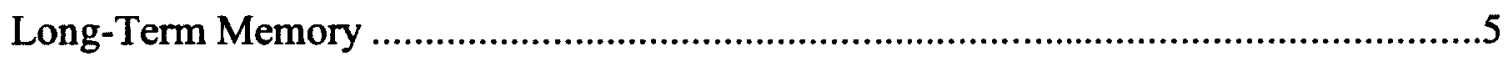

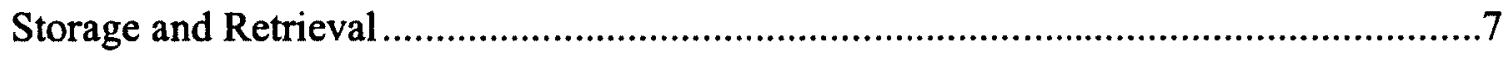

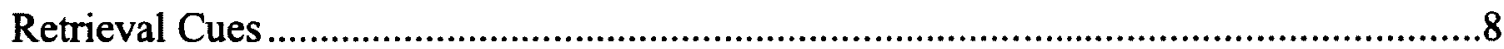

Type of Retrieval Cues and Lineup Identifications ..................................................11

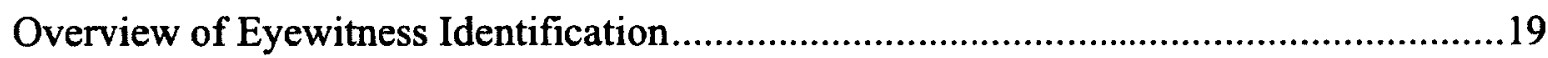

Face Recognition versus Eyewitness Identification...................................................19

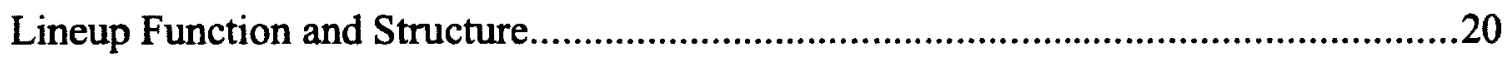

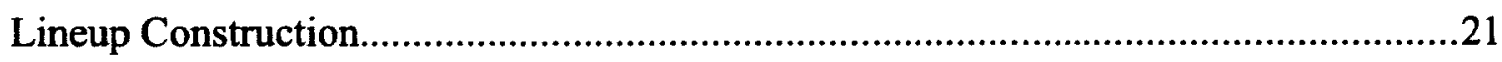

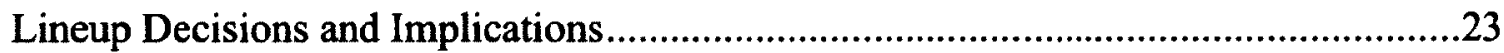

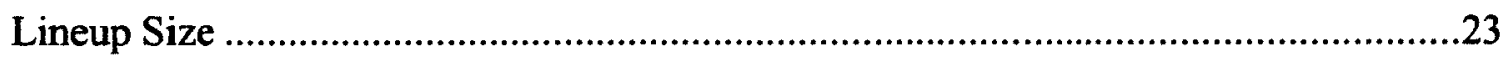

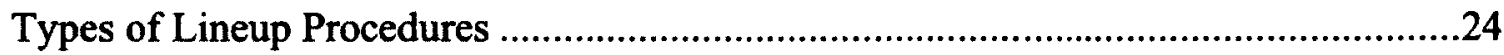

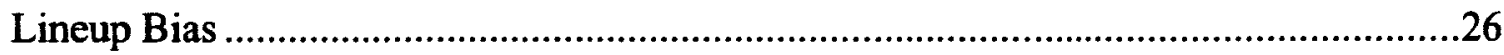

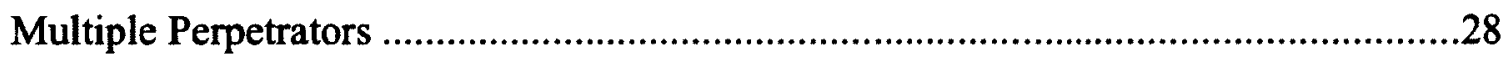

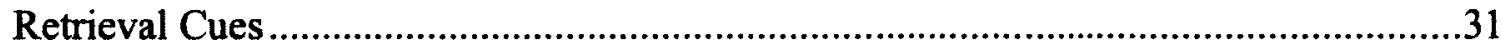


Overview of Studies.

Study 1

Study 2 .32

Study 1: Increasing Correct Identifications of Multiple Perpetrators Through the use of

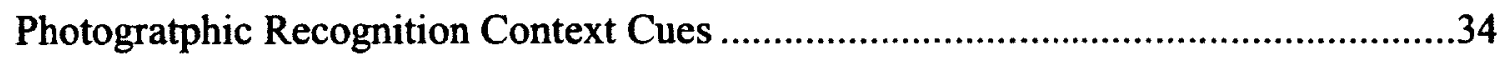

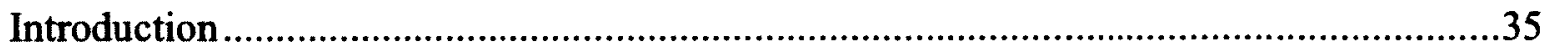

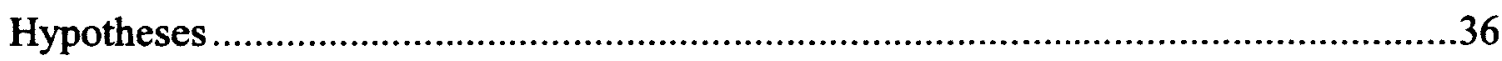

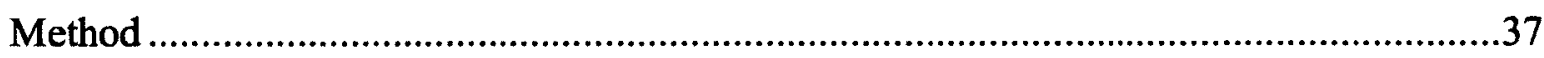

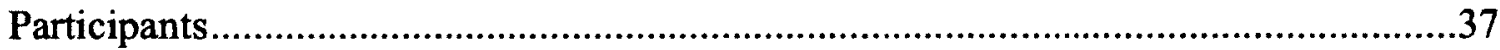

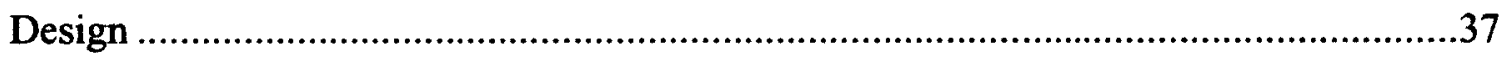

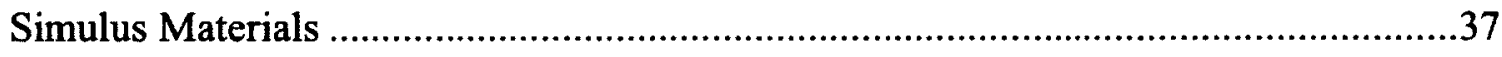

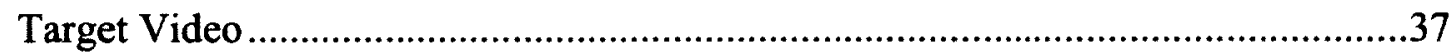

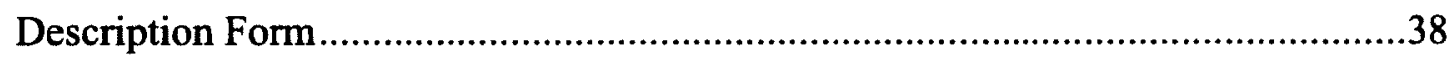

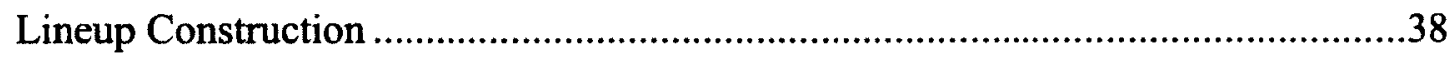

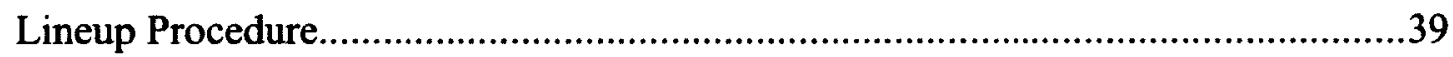

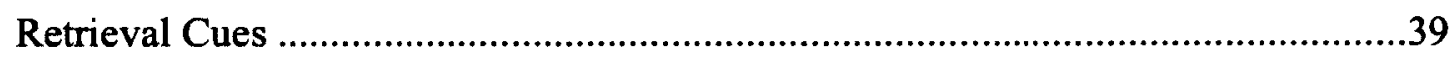

Deception Awareness Questionnaire ......................................................

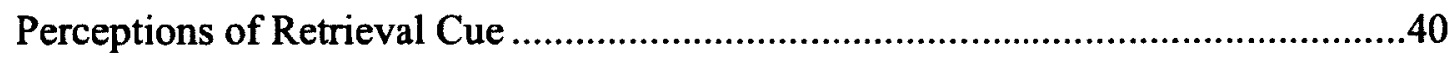

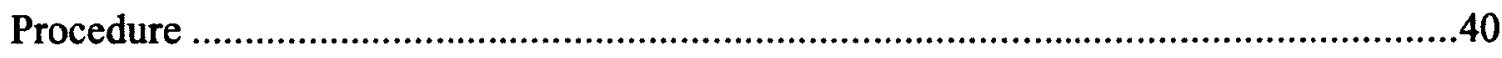

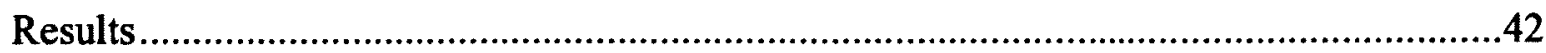

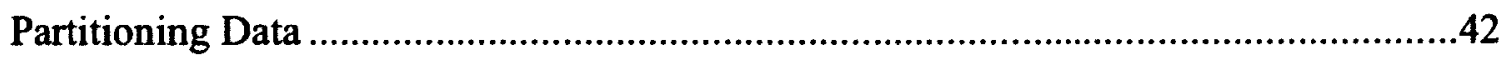

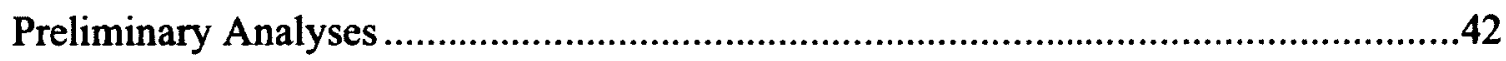

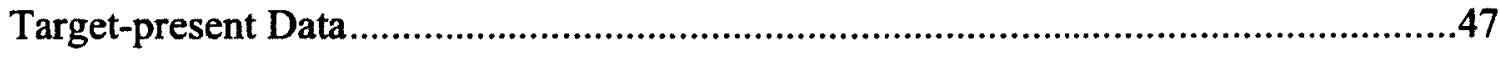


Cue Accuracy .47

Lineup Member Choosing Rates ...........................................................................49

Witness' Perception of Cue Accuracy......................................................................49

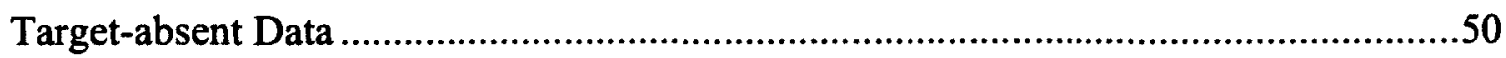

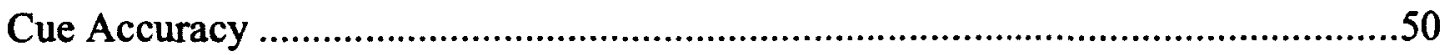

Witness' Perception of Cue Accuracy ................................................................51

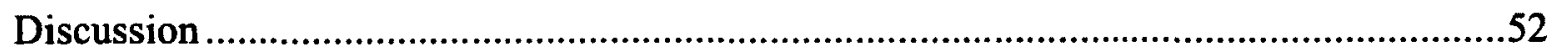

Study 2: An Investigation of Retrieval Cue and Instruction Bias of the Identification of

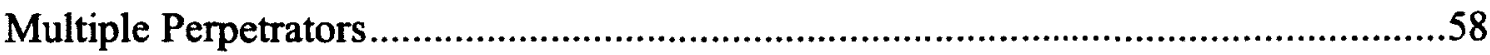

Introduction

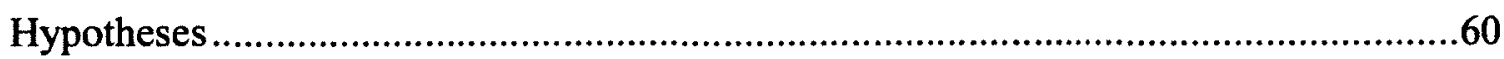

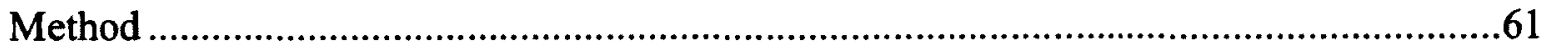

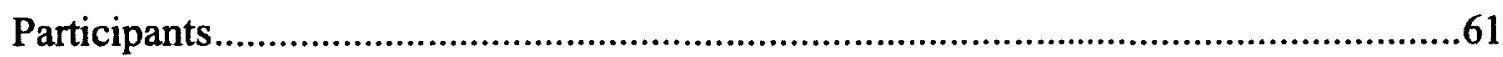

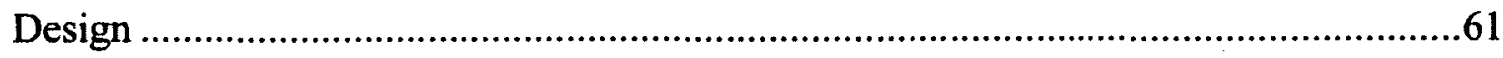

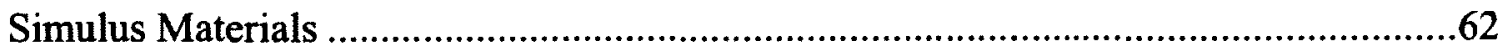

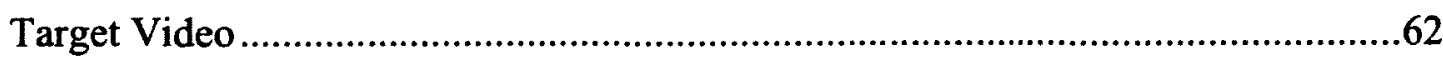

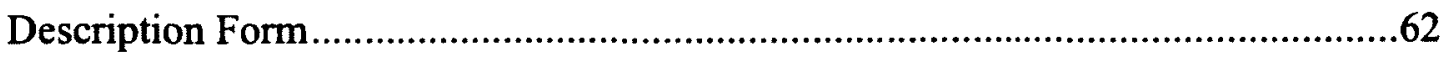

Lineup Construction .......................................................................................62

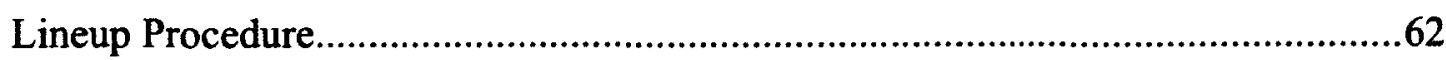

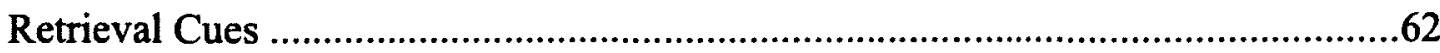

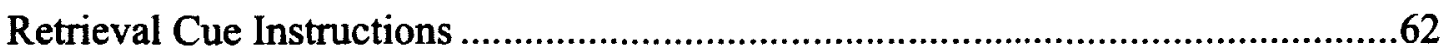

Deception Awareness Questionnaire..............................................................62

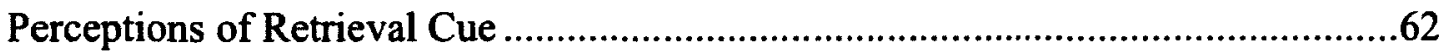




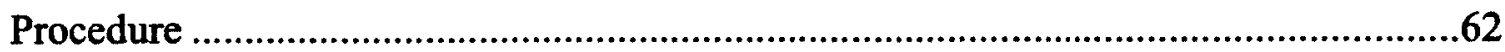

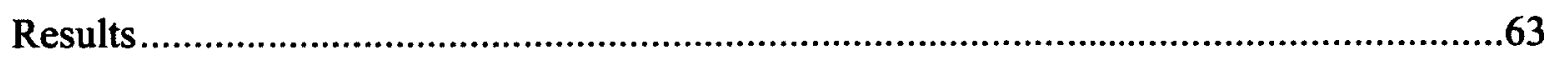

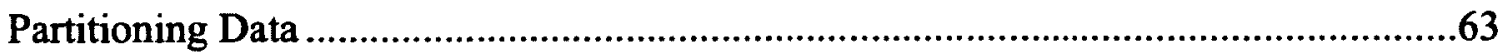

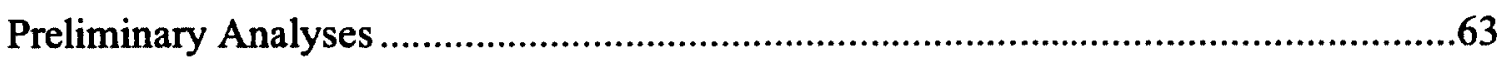

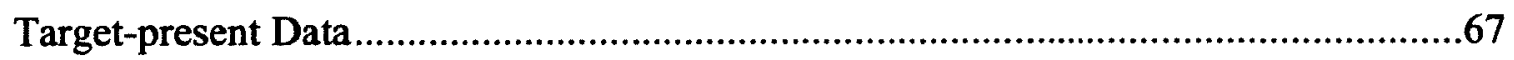

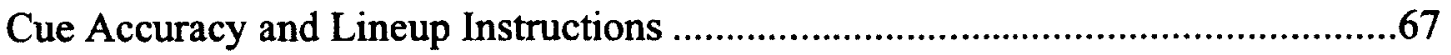

Lineup Member Choosing Rates ............................................................68

Influence of Cue Instructions on Witness' Perception of Cue Accuracy ................69

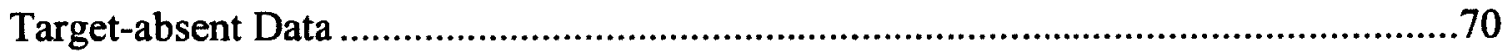

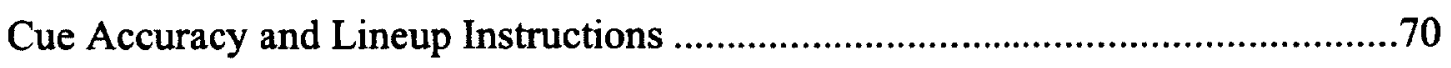

Influence of Cue Instructions on Witness' Perception of Cue Accuracy .................71

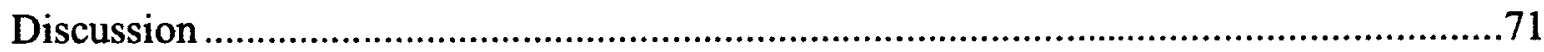

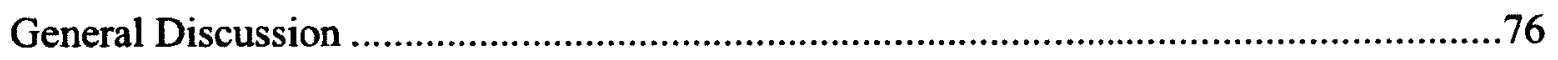

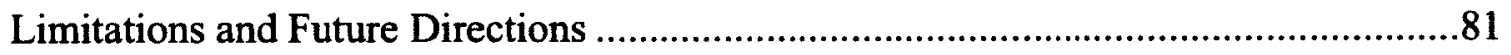

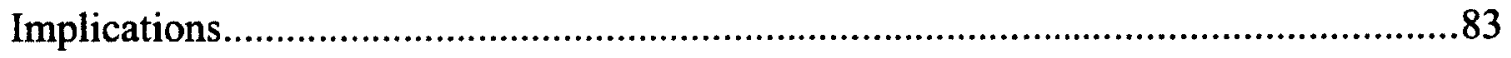

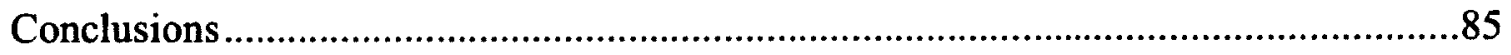

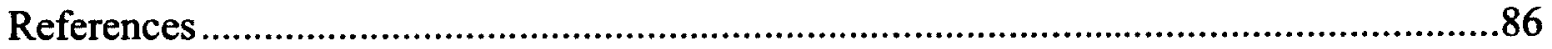




\section{List of Tables}

Table 1: Chi-Square Statistic for Comparisons in Identification Accuracy Across all Conditions

Table 2: Chi-Square Statistic for Comparisions in Identification Accuracy of

Confederates in each Perpetrator Role Collapsed Across Cue Type

Table 3: Chi-Square Statistic for Comparisions in Identification Accuracy of Perpetrator

Role Collapsed Across Confederate and Cue Type .45

Table 4: Identification Descision Rates $(n)$ as a Function of Cue Accuracy and Target

Role .46

Table 5: Identification Decision Rates $(n)$ as a Function of Cue Accuracy. .48

Table 6: Chi-Square Statistic for Comparisons in Identification Accuracy Across all

Conditions When Given Neutral Instructions. .64

Table 7: Chi-Square Statistic for Comparisions in Identification Accuracy of

Confederates in each Perpetrator Role Collapsed Across Cue Type and Instruction Type

Table 8: Chi-Square Statistic for Comparisions in Identification Accuracy of Perpetrator

Role Collapsed Across Confederate, Cue Type, and Instruction Type.

Table 9: Identification Descision Rates ( $n$ ) as a Function of Cue Accuracy and Target

Role with Neutral Instructions .66

Table 10: Identification Decision Rates $(n)$ as a Function of Cue Accuracy and Instruction Type .67 


\section{List of Appendices}

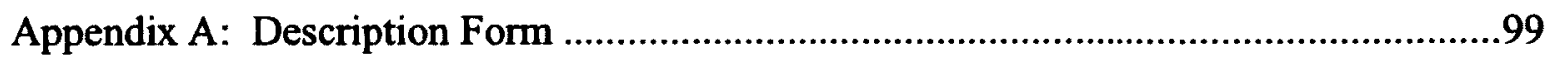

Appendix B: Simultaneous Lineup Form ..........................................................100

Appendix C: Deception Awareness Questionnaire...............................................101 
An Investigation of Retrieval Cues as a Method to Improve Eyewitness Identification Accuracy of Multiple Perpetrators

\section{General Introduction}

Crimes committed by multiple perpetrators continue to rise both in Canada and the United States (Bureau of Justice Statistics, 2007; Statistics Canada, 2001). In Canada, approximately $15 \%$ of homicides where an adult is accused involves multiple perpetrators and just over half (52\%) of homicides where a youth is accused involves multiple perpetrators (Statistics Canada, 2008). Similarly, in the United States $20.3 \%$ of homicides in 2005 involved multiple perpetrators (Bureau of Justice Statistics, 2007). Despite this reality of multiple perpetrator crime there is limited empirical research investigating this issue. The research that does exist examining this issue suggests that identification accuracy decreases as the number of perpetrators involved in the crime increases (Clifford \& Hollin, 1981; Shapiro \& Penrod, 1986; Wells \& Pozzulo, 2006). The purpose of the present study is to examine the use of a visual retrieval cue as a method for improving identification accuracy of multiple perpetrators. This retrieval cue will be used to investigate the position that a visual retrieval cue will facilitate the retrieval of accurate information that will improve accuracy during recognition tasks.

In a typical eyewitness paradigm, a person (witness) observes an event (a crime) that involves other individuals (perpetrators). Aspects about the event and individuals are encoded in memory. However, what is encoded in memory and how well it is encoded will vary based on many factors such as individual witness factors and various aspects of the event itself (Malpass, 1996). After the event, typically a period of retention follows before the witness is asked to recall information about the event and perpetrator(s) and 
before identifying the perpetrator(s) from a lineup. During this time, the memory trace of the event may weaken or change due to memory decay or as a result of the observer being exposed to contradictory information (Malpass, 1996). Eyewitness descriptions and identifications are reliant upon an individual's memory system.

The vast literature on memory provides direction on how and when cues can facilitate recall and recognition. Retrieval cues have been found to be successful at memory facilitation in both semantic and episodic memory (Memon \& Bruce, 1985). Thus, if a witness is having difficulty retrieving information providing a cue (i.e., additional information regarding the original event) is likely to facilitate the retrieval of the accurate information.

The introduction of this dissertation is organized as follows. First, an introduction and general overview of memory including a description of the various memory types, the retrieval process, and retrieval failure is presented. This section is followed by a broad discussion of the retrieval cue literature, as well as a discussion of the function of retrieval cues as a method to improve identification accuracy of multiple perpetrators. Next, an introduction to theory and research on eyewitness identification is provided that includes the topics of identification accuracy of multiple perpetrators, lineup function and procedures, and the measurement of accurate and false identifications. Finally, a summary of the purpose and hypotheses for the two proposed studies are presented.

\section{Memory}

Memory can be defined as the mental process of acquiring and retaining information, that can later be retrieved (Ashcraft, 2006). The mental storage system that facilitates this process is comprised of three distinct processes or stages: sensory memory, 
that includes acquisition or encoding of the new information, short-term or working memory, and long-term memory. The standard model of human memory proposed in the late 1960's by Atkinson and Shiffrin (1969), suggested that the stages of memory worked in a sequential order, with each stage having to be completed before the next stage could be accessed. The standard model of human memory was revised in 1976 to incorporate the idea of simultaneous processing rather than sequential processing (Ashcraft, 2006). This revision allowed for two stages of memory to be active at the same time. Although there are many more elaborate models of memory, for the purpose of the present thesis this more basic model, the standard model of human memory, is adequate.

\section{Sensory Memory}

Sensory memory is considered the first stage of the memory system. Stimuli from the environment enter the processing system and are perceived by the corresponding sense modality (i.e., vision, touch, smell, hearing, and taste). It is believed that there are as many sensory modalities as there are kinds of stimulations that can be sensed.

Information can be stored in sensory memory for a very, brief period of time, approximately one-tenth of a second. During this brief period some of the information that is perceived is encoded and passed along to the short-term memory store, while other information is lost (Ashcraft, 2006). In relation to eyewitness memory, sensory memory is used when the individual is witnessing the critical event.

\section{Short-Term Memory/Working Memory}

Short-term memory, also called primary memory or working memory, refers to the brain system responsible for the temporary storage and manipulation of information that is necessary for various functions including language comprehension, arithmetic, and 
reasoning (Baddeley, 1992). This system has the capacity to hold 7, plus or minus 2 chunks of information (Miller, 1956). Anything more exceeds the storage capacity of the short-term store. The term "working memory" has essentially replaced the term shortterm memory as working memory represents the system's active role in processing information (Baddeley, 1992; Nilsson \& Larsson, 2007). Working memory operates at a fully conscious level. Storage of information at this stage is short-lived and temporary. Basically, the system maintains the subsidiary information required for the present task. Once that task has been completed the subsidiary information is no longer required and therefore is no longer maintained in working memory (Ashcraft, 2006). Working memory also is responsible for the transfer of information to long-term memory. In order to do so, the information to be encoded and stored must be attended to and maintained (Ashcraft, 2006).

The original system proposed by Atkinson and Shffrin (1968) suggested a unitary short-term memory store that also functions as a working memory. Recently, a triparate system of working memory has been proposed by Baddeley (1992). This new system suggests that working memory is comprised of three sub-components: the central executive, which is responsible for attentional control and also controls two slave systems; the visuospatial sketch pad allows for the manipulation of visual images; and the phonological loop where speech-based information is stored and rehearsed (Baddeley, 1992). Although working memory is separate from long-term memory, the two systems are very closely related. Working memory is responsible for transferring newly acquired information to long-term memory, as well as determining when to initiate a search of the long-term memory. 
Short-term memory is an important component to eyewitness memory because this system is responsible for transferring and encoding the information acquired during the sensory phase. This process is critical because any information that is not encoded and transferred is lost and cannot be retrieved at a future time. As a result, important information regarding the crime and the perpetrator may be lost.

\section{Long-Term Memory}

Long-term memory is the portion of memory responsible for the permanent storage of information (Baddeley, 1999; Thompson \& Madigan, 2005). Some theorists suggest that the capacity of the long-term store is unlimited (Groeger, 1997; Landauer, 1986; Standing, 1973) and therefore information can be stored indefinitely (Weiten \& McCann, 2007). As such, memory never disappears, rather access to these memories becomes more difficult over time (Baddeley, 1999). Long-term memory is divided into two distinct memory systems to accommodate declarative memory and non-declarative or procedural memory (Weiten \& McCann, 2007). The declarative memory system is responsible for the storage of factual information including the recollection of words, names, faces, ideas and concepts. Conversely, procedural memory is responsible for the storage of actions, skills, operations, and conditioned responses (Weiten \& McCann, 2007).

Tulving $(1986,1993,2002)$ further subdivided declarative memory into semantic and episodic memory. Although both of these systems are responsible for factual information the systems are responsible for different types of factual information. Specifically, semantic memory is responsible for more general facts and knowledge relating to concepts and ideas as well as how to relate those concepts and ideas through 
language. Episodic memory is responsible for a person's autobiographical memory, that is memory for personal experiences and for the specific people, objects, and events that have been experienced including the time and place of the experience (Cohen, 1996). It is this episodic memory system that is of particular interest when considering eyewitness memories. There are three notable distinctions between semantic and episodic memory. The first is that episodic memories are temporally dated where semantic memory is typically stored undated and there is no memory of when the information was learned (Weiten \& McCann, 2007). The second distinction involves how the information is acquired. The storage of personal experiences within episodic memory is typically stored without conscious intention whereas information in semantic memory is typically intentionally learned and memorized in order to maintain the information (Cohen, 1996; Thompson \& Madigan, 2005). The third distinction involves how the information is retrieved from episodic and semantic memory. Retrieval from semantic memory is implicit in nature. Also, because semantic memory stores generic knowledge the memories are decontextualized. As a result, the retrieval from semantic memory is not dependent on contextual information (Tulving, 1972). In contrast, retrieval from episodic memory is explicit and operates at a conscious level. Episodic memory is unique in that it is the only memory system that operates backwards in time at the point of retrieval (Tulving, 1985). That is, in order to acquire the desired information, the rememberer must travel back in time to a given, specific episode. Given that episodic memory are personal experiences, episodic memory is strongly dependent on contextual cues to facilitate the retrieval of the desired information (Tulving, 1972). Eyewitness memory relies most heavily on episodic long-term memory. It is this type of memory that is 
required to relate information regarding the description of the perpetrator, as well as recognizing the perpetrator from a lineup.

\section{Storage and Retrieval}

How information is stored and retrieved in long-term memory is unknown, however several theories have been proposed to explain this phenomenon. Retrieval refers to accessing information that has been stored in memory (Ashcraft, 2006; Roediger \& Guynn, 1996). The quality of information that can be retrieved from long-term memory is dependent upon how well the information has been encoded and stored (Roediger \& Guynn, 1996). One theory that has been proposed to explain memory retrieval is the encoding specificity principle. The encoding specificity principle suggests that memory retrieval may be facilitated by the presence of the right cue (Tulving $\&$ Thomson, 1973). Specifically, a cue may facilitate memory retrieval if the information relating to that cue was encoded into memory along with the to-be-remembered target stimulus. Conversely, if the information relating to that cue was not stored during the target stimulus exposure, the cue will not facilitate retrieval.

This theory was originally developed to explain semantic context on the recall and recognition of verbal material. Thomson and Tulving (1970) completed one of the first experiments to demonstrate the encoding specificity principle, specifically, this principle asserts that a cue may help to facilitate recall only if it is present and encoded with the tobe-remembered target. During the study phase of this experiment, participants were presented with pairs of words that were semantically unrelated or vaguely related (e.g., glue) to the target word (e.g., chair). During the test phase of the experiment, participants were either presented with the weak cue (e.g., glue) or a strong cue (e.g., table) that was 
not presented or paired with the target word during the study phase, but would have a strong semantic relationship to the target word. In this situation, the encoding specificity principle would predict that the weak cue would facilitate better recall than the strong cue because the weak cue was encoded with the target. Results of this study supported this prediction. Results indicated better recall performance when the participant was presented with the weak cue compared to the strong cue.

Based on the encoding specificity principle, retrieval cues play a significant role in the type of memory trace that will be accessed during the memory retrieval stage, that in turn, will have a significant impact on recall and recognition accuracy. In the applied memory area of eyewitness identification, retrieval cues may facilitate (or hinder) lineup identification accuracy. Unique to a multiple perpetrator crime is the opportunity to use the photo of one perpetrator as a retrieval cue for the other perpetrator involved in the crime. The assumption is that presenting the witness with a photo of one of the perpetrators will facilitate the retrieval of the image of the other perpetrator (because the information pertaining to the cue was stored in memory at the same time as the image of the perpetrator to be identified, thus allowing the witness to identify the perpetrator from the lineup).

\section{Retrieval Cues}

The term retrieval cue can have many different meanings or implications depending on how the term has been operationalized by the researcher. For example, this term can refer to cue, context cue, context reinstatement, and environment reinstatement (see Thomson, 1988). Generally the aforementioned terms tend to be synonymous. These terms refer to the use of a reminder or memory prompt that was present during encoding 
that may facilitate the retrieval of a memory when presented to the individual during the retrieval process. Anderson and Bower (1972) suggest that contextual information is comprised of the physical characteristics of the item, implicit associations with the item, as well as cognitive elements including the individual's physiological state and obvious external cues present at encoding. Tulving (1983) also proposed a broad definition of context. Tulving suggests that context is the "setting" or "cognitive environment" where the target is presented. Tulving acknowledges that the term context can be rather ambiguous. As a result, he advises that the term context be used to designate a particular manipulation. The current dissertation will define context as any cues, both implicit or explicit, present at the time of encoding.

One issue of contention concerning the use of retrieval cues in the facial recognition literature concerns the definition and breadth of the term 'cues'. Cues or context reinstatement have taken many forms including the use of background and photo orientation, encoding and retrieval environment, target clothing, and accompanying faces present at encoding and recall. These studies have produced disparate results. However, due to the large variation in techniques it is difficult to determine which techniques are successful for memory facilitation compared to others. Of further concern is the occurrence of studies using combinations of similar cues as a means of memory facilitation. For example, Cutler, Penrod, and Martens (1987) had multiple context reinstatement conditions. In one condition labeled the interview condition, participants engaged in a guided interview, reviewed photos of the crime location and bystanders, as well as re-read their initial description that they provided after witnessing the event. Although the results had a positive effect on identification performance under most 
conditions, the difficulty is discerning the impact of each individual element on identification. It is possible that one element has a positive influence on identification accuracy, while another may interfere with retrieval and have a negative impact on identification. Overall, it has been suggested that context reinstatement does facilitate recognition.

Literature reviews have been conducted that examine the research completed on context reinstatement and recognition (e.g., Memon \& Bruce, 1985); however, these reviews have indicated that the results are inconsistent. At present, no formal, systematic analysis of the area examining overall significance levels and effect sizes has been completed. From the reviews that have been completed it is not possible to determine which context reinstatement methods are successful, under what conditions, and what other factors may influence identification accuracy.

Overall, research has indicated that recognition of a previously presented target is impaired when the context of the target or event is altered at the time of recognition (Thomson, 1988). Context cues have been examined in both semantic and episodic memory (Memon \& Bruce, 1985). Context cues have been found to be successful at memory facilitation in verbal recognition of words where other words are used as context (Meyer \& Schvaneveldt, 1976) and where sentences are used to provide context (e.g., Tulving \& Gold, 1963). Context effects also have been demonstrated to facilitate the recognition of letters by using words as context (e.g., Reicher, 1969; Wheeler, 1970) as well as in the recognition of pictures (Biederman, 1972; Biederman, Glass, \& Stacey, 1973; Palmer, 1975) and in the identification of familiar faces (e.g., Bruce, 1979, 1983 as cited in Memon \& Bruce, 1985). Overall, the results from these studies are consistent 
across experimental paradigms, demonstrating a positive effect of context on semantic memory facilitation.

Despite the generally consistent findings of context effects with semantic memory, context effects are found to vary considerably in the facilitation of episodic memory. Results tend to vary as a function of the type and characteristics of the stimulus employed, the type of contextual manipulation, and the type of memory test utilized (Memon \& Bruce, 1985). The goal of this dissertation is to examine cues for the facilitation of episodic memory in an applied context. More specifically, cues will be used to facilitate eyewitness recognition with a lineup task.

\section{Type of Retrieval Cues and Lineup Identifications}

The definition of context in facial memory studies has varied considerably. For example, some studies have defined context in terms of faces that accompany the target face during the encoding phase (Bower \& Karlin, 1974; Watkins, Ho, \& Tulving, 1976; Winograd \& Rivers-Bulkeley, 1977). Winograd and Rivers-Bulkeley (1977) completed two experiments to investigate the effects of context change on face recognition. The first experiment consisted of two trials. In the first trial (i.e., the study phase), participants were presented with 36 photographs of male-female pairs and were asked to rate the compatibility of the two individuals presented. In the second trial (i.e., the test phase), participants were presented with 63 photographs of male-female pairs and were asked to indicate if the pictures presented were old or new faces. In the second trial, context was manipulated. Context was characterized by the presence of the other face, such that context would be changed if the target face was not presented with the face it was originally paired with during the first trial. Three context manipulations were 
constructed: 1) same context condition, where the pairs were presented together as they were in trial $1 ; 2$ ) deletion of context, where photos were shown alone and;3) substitution of context where old photos were paired with new photos. Results from experiment 1 indicated that recognition of previously viewed faces was substantially impaired when the context had been altered from trial 1. Deletion of context had the largest impact on correct identification compared to the substitution of context condition. These results were replicated in experiment 2.

In facial memory studies, context also has been defined as the background in which the target was presented (Beales \& Parkin, 1984; Davies \& Milne, 1985; Memon \& Bruce, 1985; Parkin \& Hayward, 1983; Thomson, 1981; Thomson, Robertson, \& Vogt, 1982). Thomson, Robertson, and Vogt (1982) completed one of the most comprehensive examinations of the influence of background reinstatement on identification accuracy. Robsertson and colleagues completed seven similar studies investigating this phenomenon. Participants were informed that the study was regarding person recognition and instructed to carefully study the slides that would be shown. A series of 36 slides were shown to the participant (the study phase) followed by a short distraction task. Next, the participants were shown a series of 24 slides, half of which were slides of people depicted in the previous slide series. There were four different test slide conditions. In the first condition the target was depicted exactly the same as in the study phase including the same orientation, clothing, and background. In the second condition, the target was presented against a blank background in different clothing. In the third condition, a new person was depicted in the same orientation, clothing, and background as a slide during the study phase. In the last condition, a new person was depicted against 
a blank background wearing clothing that was not previously viewed. Participants were asked to indicate if they recognized the individual from the previous slides. Results from this study indicated that when a person from the study phase was presented with a different background and different clothing, participants had severe difficulty recognizing the individual. The correct identification rate was reduced by over $50 \%$. However, there was only a slight tendency to falsely identify an individual as being previously seen when presented in a previously seen context. Overall, these results suggest that contextual conditions are strongly related to person recognition. However, false identification rates were found to increase when a new target was presented against a previously viewed background.

One possible explanation for the increase in false identifications when a new target was presented against a previously viewed background may be that in the absence of a contextual cue, the target does not bear sufficient resemblance to the perpetrator for the witness to make an identification. However, when a context cue is presented, the witness is more likely to make a false identification due to the familiarity of the context (Sanders, 1984).

Context also has been defined in terms of the clothing that the target wore at the time of encoding (Brutsche, et al., 1981 as cited in Memon \& Bruce, 1985; Sanders, 1984; Thomson, 1981; Thomson et al., 1982). Sanders (1984) examined clothing as a potential context cue as a means to facilitate recognition. In this study, participants were informed that they were participating in an experiment regarding reactions to videotaped or photographed faces. Participants then viewed a video of a simulated robbery and were asked to pay close attention to the faces that were presented. Following the video, 
participants completed a filler task during which they were asked to rate faces of 60 coloured photographs for personal attributes (e.g., intelligence, etc.) and identify the facial feature that was most influential in their rating. Participants then were presented with one of eight video lineups. Lineup members were presented with the same appearance and in the same physical setting as the incident, the same appearance but different physical setting, different appearance, that was altered by wearing different clothing and different glasses, but same physical setting, or different appearance and different physical setting. Lineups were either target-present or target-absent. Lineup members were presented sequentially to the participant and the participant was asked to reserve their decision until all six lineup members had been presented.

Results from this study indicate that appearance context cues have a strong influence on identification responses. Participants were more likely to identify a lineup member when their appearance was the same as seen in the incident, regardless of whether that person was the target or an innocent. However, the environmental context cue had no effect on identification. It is important to note that there are a number of methodological issues with this study. Primarily, the filler task used in this study is problematic for subsequent recognition tasks. Having participants view photographs of faces may interfere with the memory trace of the target face. Moreover, research has indicated that having participants rate the faces on personal attributes and facial features facilitates deeper processing and encoding. As a result, the participant may have difficulty recognizing the target after exposure and encoding numerous faces during the filler task. As a result, these participants may be even more reliant on appearance contextual cues because these cues may be most distinctive in comparison to facial 
features.

Another way in which context has been defined is in terms of the environment where encoding and testing is conducted (Davies \& Milne, 1982; Wagstaff, 1982). For example, Davies and Milne (1985) examined the impact of environmental context on facial recognition. Thirty-two homemakers participated in the experiment. Participants were situated in a laboratory that was full of visual cues to increase the saliency of the context. Ten minutes into the experiment the participant was confronted with the female target. Participants returned to the laboratory a week later and were shown to the same room as where the participant completed the first portion of the experiment or was shown to a different room. Participants were then asked to provide a description of the female target. Half of the participants were given a 'Guided Memory' procedure whereby participants were instructed to think back to the event, revive the emotions they felt during the incident, and visualize the target. The other group was asked to recall as much as they could with no further instructions or prompting. Following the verbal recall of the target, participants worked with an operator to complete a composite of the target. Participants also were asked to review mugshot photos and indicate if they recognized the target as well as provide an estimate of the target's height, weight, and age.

Results from this study indicated that participants were able to create a more recognizable composite after completing a Guided Memory interview compared to a freerecall interview. This improvement was further accentuated when the interview and composite were completed in the same room as the original encounter with the target. No significant effects of context were found for estimates of height, weight, and age of the target. Identification of the target from the mugshot book was highest for participants in 
the guided memory condition, regardless of the room. However, it should be noted that the overall performance of participants on the recognition task was low.

Context also has been defined in terms of having a witness re-read a description of the perpetrator prior to making a lineup identification. For example, Cutler and colleagues (1986) examined the influence of various kinds of context reinstatement. The four techniques to reinstate context were varied in a complex fractional factorial design including mnemonic techniques in the form of the cognitive interview (Geiselman, et al., 1984); physical cues in the form of nine photographs depicting where the crime occurred and the victim; re-reading one's own description which included a 40-item questionnaire and checklist regarding the offender's appearance; and re-reading another witness' description of the offender and the event.

The only context variable that produced a significant interaction effect was rereading one's own description. Re-reading one's own description maintained performance across time intervals, such that their identification accuracy was almost the same after a one-week delay (64\%) and after a one-month delay (60\%). There also was an interaction between re-reading one's own description and target presence in the lineup. When the target was absent from the lineup, participants who re-read their description provided a higher correct rejection rate (74\%) compared to participants who did not reread their description (60\%). However, when the target was present in the lineup, rereading their description produced a lower correct identification rate (50\%) compared to participants who did not re-read their descriptions (68\%). This effect was qualified by a significant three-way interaction of target presence, reading one's own description, and offender's disguise. The above effect only was found when the observer's situation was 
difficult (i.e., the offender wore a disguise). When the observer's situation was "easy" there was no effect for re-reading the description. However, it is important to note that the condition that included the witness re-reading their description also included various other methods of context re-instatement. Therefore, it is difficult to discern how rereading the description directly impacted identification accuracy. It is possible that the use of multiple context reinstatement methods actually inhibited recognition as the witness was forced to consider and synthesize a large amount of information, that was possibly conflicting, when reaching a decision.

Recently Sporer (2007) investigated the influence of having a witness re-read their description on identification accuracy. Participants viewed a video of a simulated theft. Following the video, participants were asked to provide a free description about the film's content, target, and events. Participants then were asked to complete a face-rating checklist by rating 53 features on a 5-point Likert scale. Approximately one-week later, participants returned to complete the identification task. Half of the participants were given the opportunity to re-read their descriptions and face rating checklist. Participants who were given the opportunity to re-read their descriptions made more correct identifications compared to the control group, however this difference was not statistically significant. Participants in the context reinstatement condition also made fewer false identifications compared to the control, but this difference also was not statistically significant. Overall, re-reading the description led to a slight non-significant improvement in identification.

It is important to note that overall performance on the identification task was low, producing a mean accuracy rate of $44.4 \%$. This rate suggests that the identification task 
was rather difficult and may account for the lack of reliable findings. Typical lineup identification accuracy rates are around 70-75\% (Pozzulo \& Lindsay, 1998). The lack of reliable findings also may be the result of insufficient power given the sample size of the study $(N=54)$. The context reinstatement procedure may not have been effective because in addition to reading their free recall descriptions, participants also reviewed the face-rating checklist. It is possible that the face-rating checklist impaired recognition as participants are required to rate features that may not have been encoded in memory. As a result, the ratings on the checklist may be guesses and incongruent with their memory trace. Perhaps having participants only re-read their free recall descriptions will facilitate recognition due to the idiosyncratic elements contained in the description (Sporer, 2007).

Context also has been defined in terms of the presence or absence of guided instructions during the retrieval phase (Davies \& Milne, 1985; Geiselman, Fisher, Hutt, Sullivan, Avetission, \& Frosk, 1984; Loftus, Manber, \& Keating, 1983; Malpss \& Devine, 1981a). Malpass and Devine (1981a) had participants view a staged vandalism and five months later were asked to identify the perpetrator from a lineup. Half of the participants were given a guided interview prior to making a lineup decision. The guided procedure consisted of the interviewer providing instructions asking the participant to recall various elements of the event, specifically their feelings, memory for the environment where the event occurred, memory for the perpetrator, and their immediate responses to the event. Results indicated that identification accuracy was significantly higher for the participants who received the guided interview. Moreover, rates of choosing and false identifications were not impacted.

Overall, it appears that contextual cues that are accurate or consistent with the 
information that was originally encoded, have a small positive effect on facial recognition. Conversely, inaccurate or inconsistent contextual cues are detrimental and reduce accuracy. However, the studies investigating this phenomenon often combine different cues in the same study making it difficult to determine which, if any context cue, is effective on its own or in what combination. Another issue of concern is the forensic utility of context cues (Cutler et al., 1986). In many of the laboratory studies the contextual reinstatement cue that is examined has little forensic utility in a real world setting. The context reinstatement suggested in the current study has high forensic utility because in a situation involving multiple perpetrators it is likely that the two perpetrators are encoded simultaneously. Thus, it is likely that providing the other perpetrator will act as an effective context cue facilitating the recognition of the other perpetrator. Study 1 will examine this hypothesis. The encoding specificity principle will be used to predict when a cue is effective versus ineffective at increasing identification accuracy. Study 2 will examine the influence of the instructions that accompany the cue on identification accuracy.

\section{Overview of Eyewitness Identification}

\section{Face Recognition versus Eyewitness Identification}

The face recognition literature suggests that the presence of multiple targets results in diminished memory for the target (e.g., Megreya \& Burton, 2006). Although this literature would suggest that eyewitness identification accuracy would decrease as the number of perpetrators increase, it is not necessarily appropriate to generalize facial recognition literature to an eyewitness domain. Often the patterns demonstrated in the facial recognition literature do not replicate the results found within the eyewitness 
literature (e.g., Pozzulo \& Lindsay, 1998). Stark differences exist in the paradigms used to investigate facial recognition versus lineup identification. It is not uncommon with facial recognition paradigms for participants to know the purpose of the task, have numerous trials, and unlimited encoding time. Moreover, trials typically contain the photograph of the target. The photograph used for encoding may be identical to the photograph used at test. In contrast, lineup identification studies typically involve a participant naïve to the purpose of the study, exposure time to the target is brief, and in a different format at test (e.g., video-recorded for encoding and photograph at test). The photoarray used at test may or may not contain a photo of the target. For these reasons, it may be questionable to formulate eyewitness predictions based on the facial recognition literature. Below is a review of the eyewitness identification literature relevant to the current dissertation.

\section{Lineup Function and Structure}

The primary function of a lineup is to provide further evidence to corroborate a witness' description of the suspect (Wells, 1993). Moreover, a lineup identification provides evidence of the suspect's guilt beyond the verbal description by the witness (Luus \& Wells, 1991; Wells \& Luus, 1990). Therefore, an identification of the suspect from a lineup increases the likelihood that the suspect is guilty. Whereas if the suspect is not identified, it decreases the probability that the suspect is guilty.

Of further interest to a court of law is the probative value of a given piece of evidence (Pryke, Lindsay, Dysart, \& Dupuis, 2004). Specific to lineup procedures, the probative value of a lineup identification refers to how useful the identification of the suspect is in determining the guilt of the suspect (Pryke et al., 2004; Wells, Memon, \& 
Penrod, 2006). In experimental settings, it is possible to determine the probative value of a lineup procedure by using Baysian logic to calculate a diagnosticity ratio. This ratio is a comparison of correct identification decisions to incorrect identification decisions for a given lineup. The larger the diagnostic value of a procedure the more probative value the procedure has. A diagnosticity value of 1 does not provide any probative evidence regarding the accuracy of the identification because identifying an innocent suspect is equally likely as identifying a guilty suspect (Wells \& Lindsay, 1980).

\section{Lineup Construction}

A lineup contains one suspect and a set of distractors, known as foils, who are known to be innocent (Wells \& Turtle, 1986). Foils should be selected based on the foils' similarity to the witness' description (Luus \& Wells, 1991; Wells \& Luus, 1990; Wells, Seelau, Rydell, \& Luus, 1994). It is important for the features described by the witness to be consistent across lineup members however, non-recalled features should vary across lineup members to allow for discriminability and control for lineup heterogeneity (i.e., lineup members who look too different from one another; Wells \& Luus, 1990). In instances where there is a limited or inadequate description of the perpetrator or when the witness' description does not match the suspect, foils should be matched to the suspect rather than the witness' description. The function of the foils is to ensure that identification decisions are based on recognition memory, rather than on recall memory (Wells \& Luus, 1990). That is, a witness who has a clear memory for the perpetrator should be able to distinguish between similar looking suspects (based on the description they provided) and make an identification, whereas a witness who does not have a clear memory will not (Malpass, Tredoux, \& McQuiston-Surrett, 2007). Foils 
also serve to protect the suspect, specifically when the suspect is innocent, as the foils help protect against chance or guessing by the witness (Luus \& Wells, 1991).

Another important structural consideration is the presence or absence of the perpetrator in the lineup. In reality it is not possible to know if the suspect in the lineup is in fact guilty. However, in an experimental paradigm it is known whether or not the perpetrator is in the lineup. As a result, two types of lineups are possible: target-present and target-absent. A target-present lineup refers to a lineup where the perpetrator is among the lineup members presented to the witness, that is your suspect is guilty. There are three lineup decisions possible with a target-present lineup: a correct identification (witness identifies the guilty suspect), a foil identification (a known error) or a false rejection (no lineup member is identified by the witness). On the other hand, a targetabsent lineup is a lineup where the perpetrator is not among the lineup members presented to the witness and the suspect is innocent. Target-absent lineups also may result in three possible lineup decisions: a correct rejection (no lineup member is identified by the witness), a foil identification (a known error), or a false identification (an innocent suspect is identified).

By manipulating the presence or absence of the perpetrator in a lineup, researchers are able to calculate the rate of correct identification (the rate at which the guilty suspect is identified - target-present lineups) and the rate of false identification (the rate at which an innocent suspect is identified - target-absent lineups). It is important to examine the rate of correct identifications and correct rejections (or false positive identifications) as each type of decision has different consequences for the individual, the criminal justice system, and the community. 


\section{Lineup Decisions and Implications}

Three errors are possible with lineups, each having different implications for the suspect, witness, and society. A false rejection occurs when the witness fails to identify the perpetrator (i.e., guilty suspect) from a lineup and rejects the entire lineup. This error has negative consequences for the community as it allows the perpetrator to return to the community and potentially commit further crime.

A foil identification occurs when a witness identifies a known to be innocent individual. Consequently, this type of identification may discredit a witness and may jeopardize their future credibility as a witness in court as the witness may be perceived as having a faulty memory or as willing to report inaccurate details. This error also may prevent the witness from viewing additional lineups and having future identifications considered (Pozzulo \& Lindsay, 1999). However, a foil identification is less costly to the criminal justice system than a false identification of an innocent person because the innocent person is not prosecuted (Chance \& Goldstein, 1984).

A false identification is considered to be the most serious error because an innocent suspect is accused of a crime he/she did not commit. This identification may lead to the prosecution and possible conviction of an innocent person. In fact, eyewitness identification is the leading cause of wrongful conviction (Wells et al., 1998). Moreover, the actual perpetrator remains at large possibly to commit further crimes.

\section{Lineup Size}

In Canada lineups are typically twelve person; however, in the United States the typical lineup size is six person. There has been great debate regarding nominal lineup size (Brigham, Ready, \& Spier, 1990; Levi, 2007; Malpass, 1981; Malpass \& Devine, 
1983; Malpass, Tredoux, \& McQuiston-Surrett, 2007). Nominal size refers to the optimal number of lineup members required to decrease the likelihood of identification errors. Nominal size is an important factor to consider while constructing a "fair" lineup (e.g., all lineup members have an equal likelihood of being identified) because an innocent suspect who is placed in a small lineup would appear to be at an increased risk of being identified, especially if the witness is merely guessing (Nosworthy \& Lindsay, 1990). Nosworthy and Lindsay (1990) compared identification accuracy and false identifications rates produced by lineups varying in nominal size from 4 to 20 . Results indicated no significant difference in identification accuracy and false identification rates. This study provides evidence suggesting that using three foils is adequate for constructing a fair lineup provided that the foils included in the lineup share a reasonable resemblance to the suspect. Furthermore, Levi (2007) has found that lineups can include up to 84 members without affecting identification accuracy. Given most eyewitness research in the past 30 years has used 6-person lineups, 6-person lineups will be used in this dissertation.

\section{Types of Lineup Procedures}

The two most common lineup procedures to display lineups to witnesses are the simultaneous and sequential. In the simultaneous lineup all of the lineup members are presented to the witness at once. This lineup procedure has been criticized as affording witnesses the opportunity to make a relative judgment, that is, the opportunity to compare across lineup members (Wells, 1993). Relative judgments have been considered to be less accurate/ideal because this type of judgment may lower the threshold required to make an identification; lineup members are compared to each other rather than to a 
witness' memory of the perpetrator. When the suspect is innocent, a false positive may occur.

In order to address this criticism, an alternative procedure was developed, the sequential lineup (Lindsay $\&$ Wells, 1985). In the sequential lineup, lineup members are presented one at a time to the witness. After each lineup member is presented, the witness must decide if that individual is the perpetrator before the next lineup member is presented. This process continues until all of the lineup members have been presented to the witness. This type of lineup is considered to be superior to the simultaneous lineup procedure because this procedure encourages the witness to use an absolute judgment when making their lineup decision; that is, in order to decide if the lineup member being presented is actually the perpetrator the witness must compare the lineup member to his/her memory of the perpetrator.

Early studies comparing simultaneous and sequential lineup procedures suggested that the sequential lineup reduces false positive responding (i.e., the combination of foil and false identifications in target-absent lineups) while not significantly influencing correct identification rates (e.g., Cutler \& Penrod, 1988; Kneller, Memon, \& Stevenage, 2001; Lindsay \& Bellinger, 1999; Lindsay, Lea, Nosworthy, et al., 1991; Lindsay \& Wells, 1985; Melara, DeWitt-Rickards, \& O'Brien, 1989; Sporer, 1993). A recent metaanalysis comparing the two lineup procedures provided further support for the superiority of the sequential procedure under certain conditions (Steblay, Dysart, Fulero, \& Lindsay, 2001). A reanalysis of Steblay and colleagues' meta-analysis by McQuiston-Surrett, Malpass, \& Tredoux, (2006) suggests that the superiority of the sequential lineup procedure may vary as a function of the study methodology as opposed to the lineup 
procedure itself. For example, the method used to construct the lineup (i.e., selecting fillers) can impact identification performance (e.g., Tunnicliff \& Clark, 2000). The studies included in the meta-analysis used a variety of methods to select fillers including selection based on physical similarity, match to physical descriptions, and the experimenter selecting the fillers with no pilot testing. Differences in lineup construction methods were not considered in the Steblay et al. (2001) meta-analysis that may have led to the sequential superiority effect. More recently, Steblay and colleagues (2011) completed a new meta-analysis to examine differences between the simultaneous and sequential lineup procedures. Results from this meta-analysis were similar to the previous meta-analysis indicating that although the sequential lineup is less likely to result in an identification of the suspect, when an identification is made from a sequential lineup it is more diagnostic of guilt. Despite these findings, the sequential lineup does not appear to be ideal when dealing with child witnesses or crimes that involve multiple perpetrators (McQuiston-Surrett et al., 2006). Thus, the current dissertation will use the simultaneous lineup procedure.

\section{Lineup Bias}

A major concern is the "fairness" of a lineup. The purpose of a lineup is to secure an identification that can provide further evidence of the individual's guilt or innocence; however, it is of equal importance that the lineup be fair to all members, specifically those who are innocent (Malpass et al., 2007). Thus, lineup procedures should be designed that maximize the identification of guilty suspects, while minimizing the likelihood of an identification of an innocent suspect (Freire, Lee, Williamson, Lindsay, \& Stuart, 2004; Lindsay \& Wells, 1985; Wells et al., 2000; Wells, Rydell, \& Seelau, 
1993). One way to help ensure that a lineup is fair is to eliminate potential sources of bias. A lineup is considered biased against the suspect when the suspect stands out in some manner from the other lineup members (Malpass et al., 2007). A number of factors can introduce bias to a lineup procedure including how the lineup photos are presented to a witness (i.e., simultaneous vs. sequential), similarity/dissimilarity of foils relative to the target, clothing similarity of lineup members, and the type of lineup instructions provided prior to the lineup identification task.

Lindsay and colleagues (1987) examined the influence of clothing bias on identification accuracy. Participants witnessed a staged crime and later were presented with a lineup. Lineup clothing was manipulated producing three lineup conditions: 1) biased condition, only the suspect wore similar clothing to that worn by the perpetrator during the commission of the offence; 2) usual lineup condition, all lineup members wore different clothing from what was worn during the crime and from each other; 3 ) alike condition, all lineup members dressed alike (i.e., in white lab coats).

Results from this study indicated that with a target-present lineup, clothing had no effect on the rate of correct identification. However, with a target-absent lineup, the innocent suspect was most likely to be identified from the clothing-biased lineup. That is, when the innocent suspect wore clothing similar to the clothing worn by the perpetrator during the commission of the crime, the chance of that suspect being identified significantly increased. In comparison, an innocent suspect was less likely to be identified from the "usual lineup" and least likely to be identified from the "alike lineup". Similar studies also have reported a clothing bias resulting in an increase in false 
identifications from target-absent lineups by both adult and child witnesses (Dysart, Lindsay, \& Dupuis, 2006; Freire et al., 2004).

Another potential factor that may bias a lineup procedure are the instructions provided to the witness prior to the identification task. Lineup instructions are considered biased when the instructions suggest to the witness that the perpetrator is in the lineup (Clark, 2005; Leippe, Eisenstadt, \& Rauch, 2009; Malpass \& Devine, 1981b). Whereas, instructions are considered unbiased or neutral when they explicitly state to the witness that the perpetrator may or may not be present in the lineup (Clark, 2005; Leippe, Eisenstadt, \& Rauch, 2009; Malpass \& Devine, 1981b). Steblay (1997) completed a meta-analysis of 18 studies comparing the influence of neutral versus bias instructions on identification accuracy. Results indicated that biased instructions resulted in a significant decrease in correct rejections and an increase in false identifications. Moreover, overall choosing behaviour was affected by type of instructions such that, biased instructions significantly increased the probability of an identification attempt where neutral instructions significantly decreased the probability of an identification attempt.

In summary, any form of lineup bias increases the potential for a mistaken identification (Malpass et al., 2007). This bias may be introduced either subtly (e.g., clothing) or overtly (e.g., instructions; Freire et al., 2004). Lineup instructions/bias will be considered in Study 2 of this dissertation. Lineup instructions may interact with retrieval cue.

\section{Multiple Perpetrators}

Intuitively one could expect that an individual's memory, and subsequent identification, for several targets would be poorer than an individual's memory and 
identification for a single target. Not surprisingly, it has been suggested that as the number of perpetrators increase, identification accuracy rates would decrease as a result of perceptual overload (Wall, 1965) or encoding difficulties (Megreya \& Burton, 2006). However, it is also possible that as the number of perpetrators increase accuracy rates also increase. Consider that the presence of more than one perpetrator allows the witness to make comparative judgements between the perpetrators (e.g., comparing features, height, weight) facilitating a more accurate memory of the target persons resulting in more accurate recognition (Levine \& Tapp, 1973).

The limited eyewitness research examining identification accuracy for multiple perpetrators suggests that as the number of perpetrators increases, identification accuracy decreases (Clifford \& Hollin, 1981; Shapiro \& Penrod, 1986, Wells \& Pozzulo, 2006). Specifically, Clifford and Hollin (1981) examined identification accuracy for multiple perpetrators. Participants were shown a video of a violent (robbery) or non-violent interaction. In the video, the principle actor was either presented alone, with two accomplices, or with four accomplices. After viewing the video, the participants were asked to describe the perpetrators and the interaction and then make identifications from a 10-person lineup. Results indicated that as the number of perpetrators involved in the interaction increased, accuracy for both the description and identification decreased. This decrease in accuracy was even more pronounced for the participants in the violent condition.

Of further interest is whether an eyewitness is more accurate in identifying a perpetrator depending on the role that individual had in the commission of the offence. For instance, is a witness more likely to identify the assailant or the accomplice? 
Research examining differences in identification of these two roles remains mixed. Wells and Pozzulo (2006) found that witnesses were more likely to correctly identify the accomplice rather than the assailant in a two-perpetrator crime. This finding also is consistent with research by Geisleman, MacArthur, and Meerovitch (1993). However, other research suggests that a witness may be more likely to identify the individual who plays a more central role in the crime (i.e., the assailant) compared to an individual who plays a more peripheral role (i.e., the accomplice). Christianson and Loftus (1987) found that after viewing a traumatic event, participants were more likely to report the central details of the event and were better able to recall the critical aspects of the event. Based on this research it is suggested that in a crime involving multiple perpetrators, the accomplice would be considered a more peripheral detail relative to the assailant. As a result, a witness may be better able to recognize the assailant because this perpetrator plays a more central role in the event. This finding also is consistent with research by Dempsey and Pozzulo (2008) who found that witnesses were more likely to correctly identify the assailant rather than the accomplice in a two-perpetrator crime.

Overall, little empirical research has been completed examining identification of multiple perpetrators. The research that has been completed examining multiple perpetrator eyewitness identification indicates diminished memory and lower accuracy (Clifford \& Hollin, 1981, Shapiro \& Penrod, 1986, Wells \& Pozzulo, 2006). Therefore, it is important to identify ways to improve identification accuracy for multiple perpetrators. 


\section{Retrieval Cues}

A lineup identification requires the witness to engage their recognition memory. In some situations, a problem occurs between the storage of the information and the retrieval of the information the witness needs to complete the identification task (Thomson \& Tulving, 1970). Therefore, a lineup identification is based both on the availability of the information in the long-term memory storage and the accessibility or ease at which the witness is able to access the information from long-term memory. It is possible that the information required by the witness is available in the long-term memory store but cannot be recalled (Tulving \& Pearlstone, 1966). In this case, the information may become accessible in the presence of an appropriate cue (Tulving \& Pearlstone, 1966). The main focus of this dissertation will be to examine the use of a cue to determine when it enhances versus hinders identification accuracy.

\section{Overview of Studies}

\section{Study 1}

The first study to be conducted will examine the effect of a visual image (i.e., photo) as an effective retrieval cue for identification accuracy. The retrieval cue in this study is the photo of one of the perpetrators involved in the crime. The encoding specificity principle suggests that a cue will be effective when it is encoded in reference to the to-be-remembered stimulus. Presumably, a photo of one of the perpetrators involved in the crime would act as a recollective cue, thus increasing the likelihood the witness would correctly recognize the other perpetrator who was involved. Thus, it is hypothesized that witnesses given an accurate retrieval cue at the time of the lineup identification task will be more accurate than witnesses given no cue. Conversely, an 
inaccurate cue would not act as an effective recollective cue since the information relating to the cue was not encoded with the to-be-remembered stimulus. It is hypothesized that an inaccurate cue will lower identification accuracy versus no cue.

\section{Study 2}

Study 1 will be extended in Study 2 to examine the influence of instruction bias and retrieval cue on correct identification/correct rejection rates. The retrieval cue instructions provided in Study 1 could be considered biased instructions given the instructions imply that the person in custody (i.e., the photo cue) is guilty and therefore the instructions may act as an additional retrieval cue. As a result, the witness may consider the photo retrieval cue to be accurate and infer that the other perpetrator must be in the lineup since it is unlikely that the police would make an error when they already have correctly apprehended one of the perpetrators.

In the present study there is the potential for two retrieval cues to influence memory retrieval; the photo cue and the instruction cue. It is speculated that the "biased" instructions may act as an additional cue creating an expectation that the photo cue is correct. Conversely, the neutral instructions will not act as an additional cue because the instructions do not provide any additional information regarding the photo cue. Thus, it is hypothesized that witnesses given an accurate photo retrieval cue and biased instructions at the time of the lineup identification task will have comparable accuracy rates as witnesses given an accurate photo cue and neutral instructions. It also is hypothesized that an inaccurate photo cue and biased instructions will lower identification accuracy versus an inaccurate cue and neutral instructions. It also is 
hypothesized that accuracy rates will be comparable between witnesses given an accurate photo cue and neutral instructions and those given an inaccurate and neutral instructions. 
Study 1

Increasing Correct Identifications of Multiple Perpetrators Through the use of Photographic Recognition Context Cues 


\section{Introduction}

Multiple perpetrator crimes result in multiple suspects being arrested by police. It is possible that the police may ask an eyewitness to identify a suspect from a lineup while already having the other perpetrator in custody. Multiple perpetrator crimes therefore provide a unique opportunity to potentially increase identification accuracy by witnesses using one of the perpetrators as a retrieval cue to facilitate the recognition of the other. Research examining pairing faces as retrieval cues has been positive, resulting in increases in identification accuracy (Bower \& Karlin, 1974; Watkins et al., 1976; Winograd \& Rivers-Bulkeley, 1977).

For example, Watkins and colleagues (1976, Experiment 1) examined pairedfaces as a potential retrieval cue to facilitate recognition of another face. In this study, participants were presented with 80 pairs of faces (both male and female). During the test phase, pairs of faces were again presented and participants had to indicate which pairs of faces had been studied as a pair and which pairs had been re-paired with a different face. The context manipulations included a same context condition where the pairs were presented with the same face as during the study phase, changed context where the faces were re-paired with a different face from the study phase, or foil condition where the two different faces not presented in the study phase were paired together.

Results from this study indicated that recognition in the same context condition (i.e., face pair matched study phase) was superior to the changed context condition (i.e., faces were re-paired with a different face from study phase). The overall correct identification rate was $73 \%$ in the same context condition compared to $68 \%$ in the changed context condition. Although the correct identification rate was large, the correct 
identification rate in the same context condition was significantly higher than the correct identification rate in the changed context condition. These results suggest that recognition of an unfamiliar face is improved when accompanied by the same face that was present during encoding.

Overall, results suggest that the presentation of a face that originally accompanied another face at encoding increases recognition accuracy. It is also important to note that these results suggest that the presentation of an 'inaccurate' face can significantly decrease recognition accuracy. At present no one has examined this phenomenon using an eyewitness paradigm. With a crime that involves multiple perpetrators, it is possible to use one of the perpetrators as a retrieval cue to facilitate the recognition of the other perpetrator. According to the encoding specificity principle, retrieval cues may play an integral part in memory retrieval. A retrieval cue that encompasses the contextual features of that cue, such as a photograph, is considered to be a strong recollective cue provided that it was present and encoded with the target of interest. If these conditions are met, this accurate cue would facilitate memory retrieval and subsequent recognition of the target resulting in higher rates of identification accuracy. However if the cue is inaccurate, it will not have been encoded with the target of interest, and will result in higher rates of identification inaccuracy.

\section{Hypotheses}

1. Witnesses given an accurate retrieval cue (i.e., face) will produce higher correct identification/correct rejection rates than witnesses who are given no cue.

2. Witnesses given an inaccurate retrieval cue will produce lower correct identification/correct rejection rates than witnesses who are given no cue. 
3. Witnesses given an accurate retrieval cue will produce higher correct identification/correct rejection rates than witnesses who were given an inaccurate cue.

\section{Method}

\section{Participants}

A total of 221 students (155 women and 66 men) ${ }^{1}$ were recruited via an electronic research participation bulletin board (i.e., the SONA system) at Carleton University in the eastern region of Canada. Participants ranged in age from 17 to 46 years $(M=20.85, S D$ $=4.63$ ). Students received course credit for their participation. Thirty-two participants' data could not be used for various reasons. Specifically, four participants expressed knowing an individual in the lineup, 15 participants did not return within the 10 -day time limit to complete the study, and 13 participants experienced language issues. The participants whose data were removed from analyses on the bases of these issues were relatively evenly distributed across conditions. Analyses were thus conducted on the remaining 189 participants ${ }^{2}$.

\section{Design}

A 3 (cue; accurate vs. inaccurate vs. no cue) x 2 (lineup; target absent vs. target present) between subjects factorial design was used. The role of the target was counterbalanced across participants such that each of the two confederates assumed the assailant and the accomplice role in half of the conditions.

\footnotetext{
${ }^{1}$ No gender differences were found with identification accuracy.

${ }^{2}$ A power analysis was conducted to ensure sufficient ability to detect a difference assuming a small effect.
} 


\section{Stimulus Materials}

Target Video. All participants were shown a 90-second videotape of a staged, nonviolent crime. A close-up of each perpetrator that lasted for approximately four seconds each was included in the video. The crime commences with two men entering a parking lot. The men see and approach a parked vehicle. One of the perpetrators stands just in front of the car and acts as the look-out (i.e., the accomplice). The other perpetrator approaches the car on the passenger side. The perpetrator then begins to check each car door in sequence (i.e., passenger front door, passenger back door, driver back door, and driver front door) to see if any of the doors have been left unlocked. The front driver side door is unlocked and the perpetrator is successful at opening the door. Once the door is open the perpetrator enters the car and steals various items from the car. The perpetrator then slams the door and the two men continue to walk out of the parking lot. Both perpetrators are in view during the entire commission of the crime. The crime was videotaped twice, with each individual acting as both the thief and the accomplice.

Description Form. All participants were asked to write down everything they can remember about the event and everything that they can remember about each of the criminals $^{3}$ (see Appendix A).

Lineup Construction. Two six-person lineups were constructed; one for each perpetrator. Photos were taken of volunteers resembling each perpetrator to construct the lineups. The same photographs were used in the target-present and target-absent lineups for each perpetrator with the exception of the substitution of a similar looking confederate in place of the perpetrator in the target-absent lineups.

\footnotetext{
${ }^{3}$ The description form was used as a filler-task.
} 
Foils were chosen by having two independent judges rank order 12 photographs based on similarity to the target. The rankings were totaled across judges and the required number of photographs were chosen based on the lowest total rank indicating higher similarity. Fifteen mock witness descriptions were then used to ensure sufficient similarity/dissimilarity as per the suggestion by Luus and Wells (1991; see also Wells, Rydell, \& Seelau, 1993).

Lineup Procedure. A simultaneous lineup procedure was used. The six photos were arranged into two rows, with three pictures in each row. All six photos were presented to the participant at once. The participant was instructed to:

"Please look at the lineup photos. The criminal's picture may or may not be present. If you see the criminal, please place a check mark in the box matching the criminal's lineup number. If you do not see the criminal please place a check mark in the box marked 'Not Here."

After the participant made their lineup decision, the participant was asked to indicate what role the perpetrator played in the crime (i.e., thief or accomplice; see Appendix B). If the participant did not identify a lineup member this question was not asked.

Retrieval Cues. Two photographic cues were developed. The accurate cue was a photo of one of the perpetrators who was involved in the witnessed crime. The inaccurate cue was a photo of a similar looking confederate to one of the perpetrators who was involved in the witnessed crime. It is important to note that in order to control for clothing acting as a retrieval cue, the individuals presented as photo cues and the individuals in the lineup were not wearing clothing that was similar in either style or 
colour to the clothing that was worn by the perpetrators during the commission of the crime. Also the background of the cue photos was different from the crime background.

When the cue was presented to the participant they were given the following information:

"The police have apprehended one of the criminals involved in the crime and have this individual in custody."

Deception Awareness Questionnaire. After completing the lineup task, participants were asked two questions, one probing their knowledge of the experiment prior to participating and the second asking if they recognized any of the individuals from the lineup (see Appendix C).

Perceptions of Retrieval Cue. After completing the deception awareness questionnaire, participants were asked to provide their perceptions of the accuracy of the retrieval cue that was provided to them. Specifically, participants were asked:

"Do you feel that the single photo that was presented to you prior to the lineup was an accurate or inaccurate photo of one of the perpetrators involved in the crime?"

Participants who were not shown a cue were not asked this question.

\section{Procedure}

This study was completed across two testing sessions. All participants were randomly assigned to conditions. At the beginning of the first session, participants were informed that they were taking part in a study about children's television programming. After reading and signing a deceptive informed consent form, participants were told that the experimenter needed some time to prepare the required materials and the participant was asked to watch a short video (i.e., the stimulus video) while they waited. 
Following the video, participants were informed of the true nature of the experiment and were asked if they still wished to continue with the experiment. Consenting participants then completed a description form asking them to record everything they could remember about the event and the perpetrators (two separate descriptions). After completing the description form, participants were informed that the first testing session was complete. Participants then were asked to return for the second testing session within one week (i.e., 5-10 days) that they had previously scheduled through the SONA system. This testing session lasted approximately 45 minutes.

After the 5-10 day delay, $(M=6.38, S D=0.99)$ participants returned to the lab for the second testing session ${ }^{4}$. Each participant was shown one photographic lineup. Participants in the retrieval cue condition were informed that one of the perpetrators (the one depicted in the photograph) had been apprehended and that the police currently have that individual in custody. The participants were told that the experimenter had a photograph of that individual. Participants were given the photograph cue of the apprehended perpetrator and given three minutes to review the photograph. Following the delay, participants were given the lineup instructions and asked to examine the lineup. The photo cue was left beside the lineup allowing the participant the opportunity to refer to the cue if they chose to do so. Participants who were in the no retrieval cue condition were given the lineup instructions and asked to examine the lineup. Prior to the lineup task participants in the no retrieval cue condition were seated in the interview room and left alone for three minutes to account for the delay in the cueing condition where the participant reviewed the photo.

\footnotetext{
${ }^{4}$ Participants were tested in a different room from the first study session to help avoid the influence of any environmental context cues.
} 
After completing the identification task, participants were then asked a set of questions to determine their awareness of the deception used in the experiment and if they recognized any of the lineup members. Following the deception awareness questionnaire, participants in the photo cue condition were asked to provide their perceptions of the accuracy of the photo cue (i.e., is it a photo of one of the perpetrators). Each participant was then asked to complete a permission to use their data consent form and were fully debriefed at the completion of the second testing session.

\section{Results}

\section{Partitioning Data}

The data were separated into target-present and target-absent data to allow for the examination of lineup decisions as correct or incorrect depending on lineup type. In a target-present lineup, a correct decision is made when a witness identifies the guilty suspect from the lineup (i.e., making a selection); however, in a target-absent lineup, a correct decision is made when a witness does not identify a lineup member (i.e., not making a selection/rejecting the lineup). Thus, choosing versus non-choosing are two different behaviours with different social demands for each (Pozzulo \& Lindsay, 1998). As a result, combining the two measures of accuracy may confound the results.

\section{Preliminary Analyses}

Two confederates were used to play the role of assailant and accomplice. In order to control for differences in identification rates as a result of the confederate, each confederate assumed the assailant and accomplice role in half of the conditions. Moreover, in order to control for differences in identification rates as a result of perpetrator role, the role of the target who was to be identified from the lineup and who 
was presented as the cue was also counterbalanced across participants. Therefore, in order to collapse the data across target-present or target-absent conditions, confederate, and perpetrator role, it was necessary to determine if there were significant differences in identification accuracy as a function of these variables. A number of chi-square analyses were conducted to examine differences in identification accuracy. Preliminary analyses indicated that there were no significant differences between conditions, across confederate, or perpetrator role. See Table 1, 2, and 3 for chi-square results and Table 4 for identification rates as a function of perpetrator and cue accuracy. As a result the data were collapsed across target-present or target-absent conditions, confederate, and perpetrator role for all of the following analyses. 
Table 1

Chi-square Statistic for Comparisons in Identification Accuracy Across all Conditions

\begin{tabular}{|c|c|c|c|c|c|c|c|}
\hline & $n$ & $\chi^{2}$ & $p$ & $\phi$ & OR & $\begin{array}{c}\text { Confederate } 1 \\
\text { Correct ID }\end{array}$ & $\begin{array}{c}\text { Confederate } 2 \\
\text { Correct ID }\end{array}$ \\
\hline \multicolumn{8}{|l|}{ Target-present } \\
\hline \multicolumn{8}{|l|}{ Accurate cue $^{\mathrm{a}}$} \\
\hline $\begin{array}{l}\text { Identify thief when given } \\
\text { cue of accomplice }\end{array}$ & 17 & 0.05 & .82 & .06 & 1.6 & .44 & .50 \\
\hline $\begin{array}{l}\text { Identify accomplice } \\
\text { when given cue of thief }\end{array}$ & 14 & 0.31 & .58 & .15 & 0.19 & .43 & .29 \\
\hline \multicolumn{8}{|l|}{ Inaccurate cue } \\
\hline $\begin{array}{l}\text { Identify thief when } \\
\text { given cue of accomplice }\end{array}$ & 16 & 0.79 & .38 & .22 & 3.2 & .29 & .11 \\
\hline $\begin{array}{l}\text { Identify accomplice } \\
\text { when given cue of thief }\end{array}$ & 14 & 0.88 & .35 & .25 & 3.5 & .33 & .13 \\
\hline \multicolumn{8}{|l|}{ No cue ${ }^{c}$} \\
\hline $\begin{array}{l}\text { Identify thief when given } \\
\text { cue of accomplice }\end{array}$ & 16 & 1.00 & .32 & .25 & .36 & .38 & .63 \\
\hline $\begin{array}{l}\text { Identify accomplice } \\
\text { when given cue of thief }\end{array}$ & 15 & 1.73 & .19 & .34 & 4.17 & .71 & .38 \\
\hline \multicolumn{8}{|l|}{ Target-absent } \\
\hline \multicolumn{8}{|l|}{ Accurate cue ${ }^{\mathrm{a}}$} \\
\hline $\begin{array}{l}\text { Identify thief when given } \\
\text { cue of accomplice }\end{array}$ & 17 & 0.48 & .49 & 0.17 & 2.10 & .78 & .63 \\
\hline $\begin{array}{l}\text { Identify accomplice } \\
\text { when given cue of thief }\end{array}$ & 17 & 0.05 & .82 & .06 & 1.25 & .50 & .44 \\
\hline \multicolumn{8}{|l|}{ Inaccurate cue } \\
\hline $\begin{array}{l}\text { Identify thief when given } \\
\text { cue of accomplice }\end{array}$ & 16 & 0 & 1.00 & 0 & 1.00 & .38 & .38 \\
\hline $\begin{array}{l}\text { Identify accomplice } \\
\text { when given cue of thief }\end{array}$ & 16 & 2.62 & .11 & .40 & .14 & .50 & .88 \\
\hline \multicolumn{8}{|l|}{ No cue ${ }^{c}$} \\
\hline $\begin{array}{l}\text { Identify thief when given } \\
\text { cue of accomplice }\end{array}$ & 15 & 0.13 & .17 & .09 & 1.31 & .38 & .29 \\
\hline $\begin{array}{l}\text { Identify accomplice } \\
\text { when given cue of thief }\end{array}$ & 16 & 2.29 & .13 & .38 & .20 & .38 & .75 \\
\hline \multicolumn{8}{|c|}{$\begin{array}{l}\text { Note. Bonferroni correction for comparisons as a function of target presence in lineup ( } \alpha \\
=.008 \text { ). } \\
\text { a The cue presented was a photo of one of the confederates from the video. } \\
\text { b The cue presented was a photo of a similar looking male as one of the confederates from } \\
\text { the video. } \\
\text { cNo cue was presented. }\end{array}$} \\
\hline
\end{tabular}


Table 2

Chi-square Statistic for Comparisons in Identification Accuracy of Confederates in each Perpetrator Role Collapsed Across Cue Type

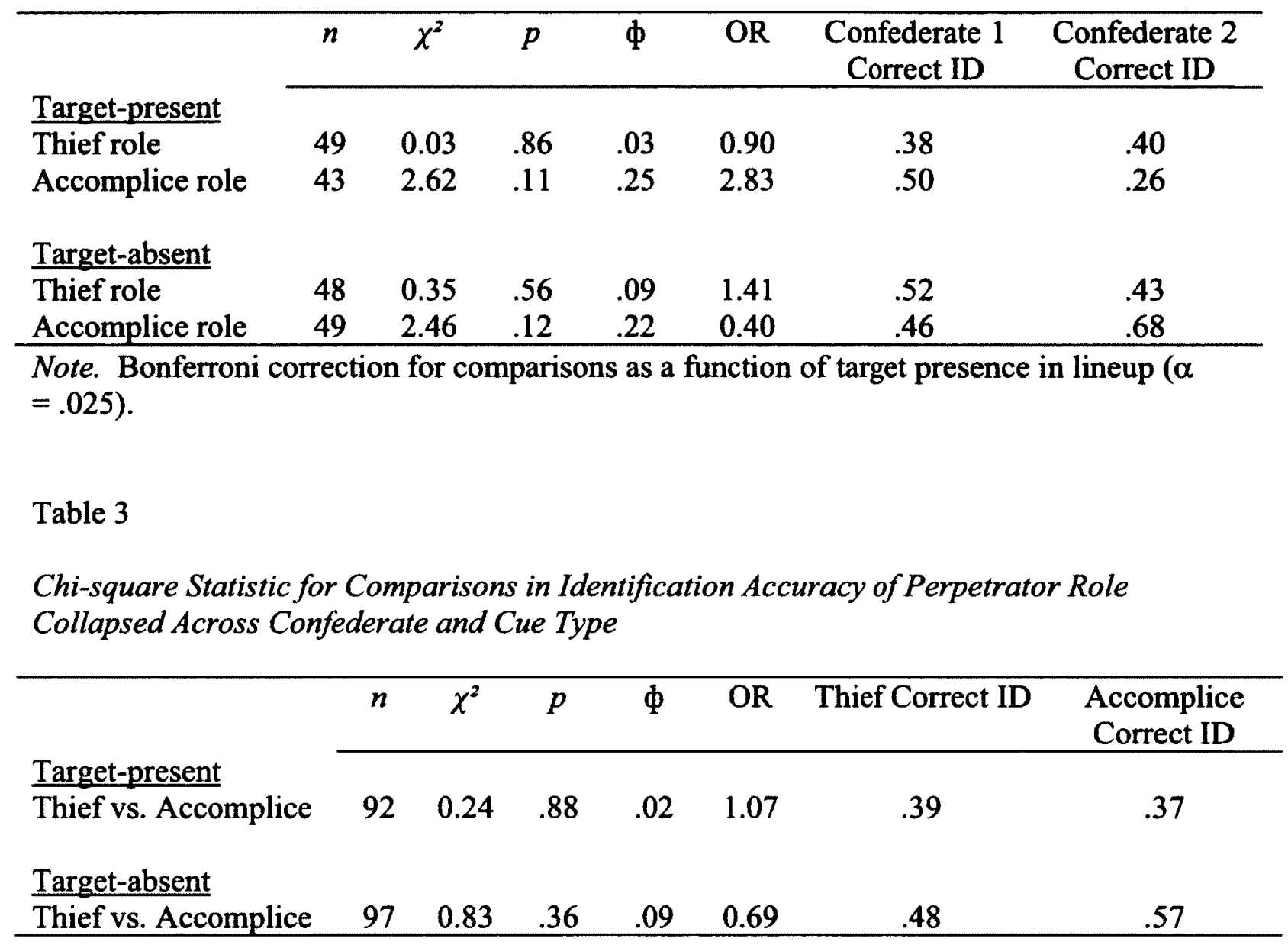


Table 4

Identification Decision Rates (n) as a Function of Cue Accuracy and Target Role

\begin{tabular}{|c|c|c|c|c|c|c|}
\hline & \multicolumn{6}{|c|}{ Cue Accuracy } \\
\hline & \multicolumn{2}{|c|}{ Accurate Cue } & \multicolumn{2}{|c|}{ Inaccurate Cue } & \multicolumn{2}{|c|}{ No Cue } \\
\hline & \multicolumn{6}{|c|}{ Target } \\
\hline & Thief & Acc & Thief & Acc & Thief & Acc \\
\hline \multicolumn{7}{|l|}{ Target-present } \\
\hline Correct identification & $.47(8)$ & $.36(5)$ & $.19(3)$ & $.21(3)$ & $.50(8)$ & $.53(8)$ \\
\hline Foil identification & $.24(4)$ & $.21(3)$ & $.19(3)$ & $.29(4)$ & $.44(7)$ & $.13(2)$ \\
\hline False rejection & $.29(5)$ & $.43(6)$ & $.63(10)$ & $.50(7)$ & $.06(1)$ & $.33(5)$ \\
\hline \multicolumn{7}{|l|}{ Target-absent } \\
\hline Correct rejection & $.71(12)$ & $.47(8)$ & $.38(6)$ & $.69(11)$ & $.33(5)$ & $.56(9)$ \\
\hline${ }^{*}$ False positive & $.29(5)$ & $.53(9)$ & $.63(10)$ & $.31(5)$ & $.67(10)$ & $.44(7)$ \\
\hline
\end{tabular}

Note. False positive rate is the rate of identification for all lineup members collapsed in the target-absent condition. 


\section{Target-present Data}

Cue accuracy. It was hypothesized that witnesses' identification rate would vary depending on the accuracy of the cue provided to them. A chi square test was used to examine differences in correct identification rates as a function of cue accuracy (i.e., accurate, inaccurate, no cue). Correct identification rates were found to significantly vary across the three cue accuracy conditions, $\chi^{2}(2, N=92)=6.76, p=.03, \phi=.27$.

In order to determine how these groups differed in terms of correct identification rates, follow-up chi-square tests were completed. All possible pairwise comparisons were completed using a Bonferroni correction $(\alpha=.02)$. It was predicted that witnesses given an accurate retrieval cue would produce higher correct identification rates than witnesses who were given no cue. Contrary to this hypothesis, the correct identification rate was comparable across the no cue and accurate cue conditions (.52 vs. .42$), \chi^{2}(1, N=$ $62)=0.58, p=.45, \phi=.10, \mathrm{OR}=0.68$. It also was predicted that witnesses given an inaccurate retrieval cue would produce lower correct identification rates than witnesses who were given no cue. Consistent with this prediction, witnesses presented with no cue produced a higher rate of correct identification compared to witnesses presented with an inaccurate cue $(.52$ vs. .20$), \chi^{2}(1, N=61)=6.61, p=.01, \phi=.33, \mathrm{OR}=4.27$. Last, it was predicted that witnesses given an accurate retrieval cue would produce higher correct identification rates than witnesses who were given an inaccurate cue. Consistent with this hypothesis, witnesses presented with an accurate cue produced a marginally higher rate of correct identification compared to witnesses presented with an inaccurate cue (.42 vs. .20), $\chi^{2}(1, N=61)=3.42, p=.06, \phi=.24, \mathrm{OR}=2.89$. See Table 5 for identification rates as a function of cue accuracy. 
Table 5

Identification Decision Rates (n) as a Function of Cue Accuracy

Accurate Cue Inaccurate Cue No Cue

$\underline{\text { Target-present }}$

Correct identification

$.42(13)$

$.20(6)$

$.52(16)$

Foil identification

$.23(7)$

$.23(7)$

$.29(9)$

False rejection

$.35(11)$

$.57(17)$

$.19(6)$

Target-absent

Correct rejection

$.59(20)$

$.53(17)$

$.45(14)$

*False positive

$.41(14)$

$.47(15)$

$.55(17)$

Note. False positive rate is the rate of identification for all lineup members collapsed in the target-absent condition. 
Lineup member choosing rates. In order to determine if providing a cue to the witnesses influenced the likelihood that the witnesses would identify a lineup member, a chi-square analysis was completed. Results indicated a significant difference in choosing rates across cue condition, $\chi^{2}(1, N=92)=9.15, p=.01, \phi=.32$.

In order to determine how these groups differed in terms of choosing rates, follow-up chi-square tests were completed. All possible pairwise comparisons were completed using a Bonferroni correction $(\alpha=.02)$. Results indicated that witnesses not presented with a cue were more likely to identify an individual from the lineup (.81) compared to witnesses who were presented with an inaccurate cue $(.43), \chi^{2}(1, N=61)=$ $9.04, p=.003, \phi=.38, \mathrm{OR}=5.45$. However, there was no difference in choosing rates between witnesses who were not shown a cue and witnesses presented with an accurate cue $(.65), \chi^{2}(1, N=62)=2.03, p=.16, \phi=.18, \mathrm{OR}=2.29$. There also was no difference in choosing rates between witnesses who were presented with an accurate or inaccurate cue, $\chi^{2}(1, N=61)=2.75, p=.10, \phi=.21, \mathrm{OR}=2.38$.

Witness' perception of cue accuracy. In order to determine if the witness' perception of the accuracy of the cue presented to them had an impact on identification accuracy, a chi-square was conducted. Only participants who provided a definitive answer to this question (i.e., yes or no) were included in the analysis. Three participants were undecided when asked about the accuracy of the cue and five participants failed to answer the question. As a result, these eight participants were excluded from this analysis. Participants who were not shown a cue also were not included in the analysis. The total $N$ used for this analysis was 53 . 
It was hypothesized that witnesses who accurately perceived the cue to be correct and witnesses who accurately perceived the cue to be incorrect would not differ in identification accuracy. Consistent with this hypothesis, there was not a significant difference in correct identification rates between witnesses who correctly perceived the cue to be accurate and those who correctly perceived the cue to be inaccurate, $\chi^{2}(1, N=$ $39)=2.67, p=.10, \phi=.26, \mathrm{OR}=3.00$. Witnesses who perceived the cue to be accurate when it was accurate were equally likely to correctly identify the perpetrator in the lineup (.53) compared to witnesses who perceived the cue to be inaccurate when it was inaccurate $(.27)$.

A second chi-square analysis was completed in order to investigate if identification accuracy differed between witnesses who were accurate or inaccurate in their perceptions of the accuracy of the cue. It was hypothesized that accuracy rates would be higher for witnesses who accurately perceived the cue to be correct compared to witnesses who incorrectly perceived the cue to be accurate when in fact it was inaccurate. Consistent with this hypothesis, there was a significant difference in correct identification rates between witnesses who were accurate in their perceptions of the cue compared to witnesses who were inaccurate in their perceptions, $\chi^{2}(1, N=22)=4.48, p=$ $.03, \phi=.45$. Witnesses who perceived the cue to be accurate when it was accurate were more likely to correctly identify the perpetrator in the lineup (.53) compared to witnesses who perceived the cue to be accurate when it was inaccurate $(0)$.

\section{Target-absent Data}

Cue accuracy. It was hypothesized that witnesses' correct rejection rate would vary depending on the accuracy of the cue provided to them. A chi square test was used 
to examine differences in correct rejection rates as a function of cue accuracy (i.e., accurate, inaccurate, no cue). Contrary to this hypothesis, correct rejection rates were not found to vary significantly across the three cue accuracy conditions, $\chi^{2}(2, N=97)=1.22$, $p=.54, \phi=.11$. The correct rejection rate was comparable across witnesses who were shown an accurate cue (.59), an inaccurate cue (.53), and those who were not shown a cue (.45). See Table 5 for identification rates as a function of cue accuracy.

Witness' perception of cue accuracy. In order to determine if the witness' perception of the accuracy of the cue presented to them had an impact on rate of correct rejection a chi-square was conducted. Only participants who provided a definitive answer to this question (i.e., yes or no) were included in the analysis. Three participants were undecided when asked about the accuracy of the cue and six participants failed to answer the question. As a result, these nine participants were excluded from this analysis. Participants who were not shown a cue also were not included in the analysis. Total $N$ used for this analysis was 57.

It was hypothesized that witnesses who accurately perceived the cue to be correct and witnesses who accurately perceived the cue to be incorrect would not differ in correct rejection rates. Consistent with this hypothesis, there was no significant difference in correct rejection rates between witnesses who were accurate in their perceptions of the cue, $\chi^{2}(1, N=38)=0.43, p=.51, \phi=.11, \mathrm{OR}=1.54$. The correct rejection rate was comparable across witnesses who perceived the cue to be accurate when it was accurate (.63) and witnesses who perceived the cue to be inaccurate when it was inaccurate (.53). A second chi-square analysis was completed in order to investigate if correct rejection rates differed between witnesses who were accurate or inaccurate in their 
perceptions of the accuracy of the cue. It was hypothesized that correct rejection rates would be higher for witnesses who accurately perceived the cue to be correct compared to witnesses who incorrectly perceived the cue to be accurate when in fact it was inaccurate. Contrary to this hypothesis, there was no significant difference in correct rejection rates between witnesses who were accurate in their perceptions of the cue compared to witnesses who were inaccurate in their perceptions, $\chi^{2}(1, N=28)=0.87, p=$ $.35, \phi=.18, \mathrm{OR}=2.14$. The correct rejection rate was comparable across witnesses who perceived the cue to be accurate when it was accurate (.63) and witnesses who perceived the cue to be accurate when it was inaccurate (.44).

\section{Discussion}

The primary objective of Study 1 was to examine if the presentation of a visual image as a retrieval cue at the time of a lineup identification would increase identification accuracy. According to the encoding specificity principle, memory retrieval may be facilitated by the presence of a cue (Tulving \& Thomson, 1973). Specifically, a cue may facilitate memory retrieval if the information relating to that cue was encoded into memory along with the to-be-remembered target stimulus. Conversely, if the information relating to that cue was not stored during the target stimulus exposure, the cue would not facilitate retrieval. This is the first study to examine this phenomenon using an eyewitness paradigm. A multiple perpetrator crime presents a unique circumstance where it is possible to use one of the perpetrators as a retrieval cue to facilitate the recognition of the other perpetrator. The encoding specificity principle suggests that retrieval cues may play an integral part in memory retrieval. A retrieval cue that encompasses the contextual features of that cue, such as a photograph, is considered to be 
a strong recollective cue provided that it was present and encoded with the target of interest. Presumably, the perpetrators would be encoded together because they were both present and involved in the commission of the offence. Thus, providing a photo of one of the perpetrators involved in the crime would act as a recollective cue, thus increasing the likelihood the witness would correctly recognize the other perpetrator who was involved.

It was predicted that witnesses presented with an accurate retrieval cue would produce higher correct identification/correct rejection rates than witnesses who were not given a cue. Contrary to this hypothesis, there was no difference in accuracy rates between witnesses shown an accurate cue and those not shown a cue, regardless of target presence. These results are somewhat inconsistent with the encoding specificity principle. According to this theory, witnesses in the correct cue condition should have produced higher correct identification/correct rejection rates because the cue face that was presented to them would have been a "strong cue" because it was present during the time of encoding and presumably was encoded with the target. As a result, the presentation of this cue would have facilitated memory retrieval, resulting in an accurate lineup decision. One potential obvious explanation for why there was not an increase in correct identification/correct rejection rates by witnesses presented with an accurate cue is that there is the potential that the cue was not encoded and stored with the target. The two perpetrators involved in the crime did play different roles in the commission of the offence (i.e., one stole items from the car while the other watched out for approaching people). As a result, it is possible that the witness paid more individualized attention to each perpetrator and as a result did not encode and store the information relating to the two individuals together. Therefore, despite the accuracy of the cue, if the information 
about the target and the cue was not encoded and stored together during the target stimulus exposure, the cue would not facilitate retrieval. Another possible explanation for the lack of difference in accuracy rates between the two cue conditions may be that the photo of the criminal presented in the lineup acted as a retrieval cue itself, resulting in a correct identification in the no cue condition. In a target-present lineup the guilty perpetrator is among the lineup photos presented. As a result, it is possible that when the witness sees the actual photo of the perpetrator it in itself acts as a retrieval cue facilitating the retrieval of the memory for that perpetrator's face. Similarly, in the accurate cue condition, it is not that the cue is not facilitating retrieval per se, the cue may just not be as beneficial in this circumstance because there is a retrieval cue inherent in the lineup. In the target-absent condition, the guilty perpetrator is not among the lineup photos presented to the witness. In the accurate cue condition, the cue may be facilitating memory retrieval resulting in the witness rejecting the lineup when none of the lineup members match their memory trace. Witnesses in the no cue condition may also engage in a similar strategy. The witness may compare their memory of the perpetrator to the photos presented in the lineup. When they are unable to locate a lineup member who resembles their memory of the perpetrator the witness rejects the lineup. Alternatively, if the witness' memory trace for the perpetrator is weak, the witness may decide to err on the side of caution and not identify a lineup member. In the no cue condition, both of these strategies would result in a correct decision when presented with a target-absent lineup.

It also was predicted that witnesses given an inaccurate retrieval cue would produce lower correct identification/correct rejection rates than witnesses given no cue. 
Consistent with the second hypothesis, in the target-present condition, witnesses presented with an inaccurate cue made fewer correct identifications compared to witnesses who were not given a cue. However, in the target-absent condition there was no difference in correct rejection rates as a function of cue accuracy. These results suggest that the inaccurate cue may not facilitate the witness' memory of the criminal because it does not match the individual's memory trace. This finding is consistent with the encoding specificity principle. This principle would argue that an inaccurate cue would not facilitate a witness' memory because the cue (being inaccurate) was not encoded at the same time as the target and as a result would not facilitate retrieval (Thomson \& Tulving, 1970). Moreover, the presentation of an inaccurate cue may cause the witness to question their memory of the perpetrators if the cue does not match their original memory trace. As a result, the witness may err more on the side of caution and apt to reject the lineup regardless of whether the target is present or not.

It also was predicted that witnesses given an accurate retrieval cue would produce higher correct identification/correct rejection rates than witnesses who were given an inaccurate cue. Consistent with this hypothesis, in the target-present condition, witnesses given an accurate cue were marginally more accurate compared to witnesses given an inaccurate cue. However, in the target-absent condition there was no difference in correct rejection rates. These results are somewhat consistent with the encoding specificity principle. This principle would argue that an accurate cue would facilitate memory retrieval because the information relating to that cue was encoded into memory along with the to-be-remembered target stimulus; whereas, an inaccurate cue would not facilitate a witness' memory because the cue (being inaccurate) was not encoded at the 
same time as the target and as a result would not facilitate retrieval (Thomson \& Tulving, 1970). These findings also are consistent with previous results in the facial recognition literature. For instance, Watkins and colleagues (1976, Experiment 1) found that recognition of an unfamiliar face was improved when accompanied by the same face that was presented during the encoding phase. Conversely, when the unfamiliar face was accompanied by a new face (e.g., an inaccurate cue) recognition of the unfamiliar face significantly decreased.

Interestingly, overall witnesses in the target-present condition who were presented with an inaccurate cue were more likely to reject the lineup than make a foil identification. That is, instead of identifying an innocent individual from the lineup, most witnesses presented with an inaccurate cue erred more on the side of caution and did not identify a lineup member. One possible explanation for this is that the inaccurate cue did not help to facilitate the witness' memory and because they are not able to access the memory the witness rejects the lineup. It is possible that the presentation of an inaccurate cue may cause some witnesses to question or second-guess their memory for the perpetrators involved in the crime. As a result, some witnesses presented with an inaccurate cue may adopt a more stringent criterion for making an identification and when no lineup members successfully meet this criterion the witness rejects the lineup. It is important to note however, that the instructions that accompanied the presentation of the cue in this study may be perceived as biased. Witnesses were instructed that the photo presented to them was of an individual the police had apprehended in association with the crime. Thus, this may have elicited inherent expectations or beliefs on behalf of the witness such as, the police would not apprehend an innocent person. Therefore, even 
if the witness believed that the cue was accurate they may have begun to question their own memory of the perpetrators. As a result, it may be that the biased instructions provided to the witness may have lead some witnesses to question their decision regarding the accuracy of the cue presented to them. Results from this study indicated that in the target-present condition, witnesses who perceived the cue to be accurate when it was inaccurate made more identification errors compared to witnesses who perceived the cue to be accurate when it was accurate. This result is concerning and suggests that perhaps the instructions that accompany a cue may be an important element to consider when presenting a cue to a witness. In order to determine if cue instructions were driving these results a second study was conducted. 
Study 2

An Investigation of Retrieval Cue and Instruction Bias on the Identification of Multiple Perpetrators 


\section{Introduction}

Numerous factors may affect eyewitness identification accuracy. One such factor is the instructions that the witness receives when presented with an identification task. Overall witnesses have strong expectations regarding a lineup identification task (Clark, 2005). Typically, witnesses believe that if the police request a lineup identification the police must believe that the suspect in custody is in fact the perpetrator of the crime (Clark, 2005). Moreover, witnesses often believe that it is their job to identify someone from the lineup (Clark, 2005). Consequently, failure to identify an individual from the lineup may be considered an error by the witness, thus making them a "bad" witness. One way to address these expectations is by providing thorough, unbiased instructions to the witness. Instructions are considered unbiased when the administrator explicitly instructs the witness that the perpetrator may or may not be present in the lineup and that if the witness does not believe the perpetrator is present in the lineup, it is acceptable to identify no one (Leippe, Eisenstadt, \& Rauch, 2009; Malpass \& Devine, 1981b). Conversely, instructions are considered biased when the administrator does not take a neutral position regarding the presence or absence of the perpetrator in the lineup and does not acknowledge the possibility of the witness to not identify a lineup member (Clark, 2005, Leippe, et al., 2009; Malpass \& Devine, 1981b).

Overall, research has indicated that the type of instruction given to a witness can have a large impact on identification accuracy. In a meta-analysis of 18 studies, Steblay (1997) found that biased instructions resulted in a significant decrease in correct rejection rates and an increase in the rate of false positive identification when the perpetrator was absent from the lineup. Overall choosing behaviour (i.e., identifying any lineup member) 
also was found to be higher when the witness received biased instructions (Steblay, 1997). As a result, biased instructions may increase the rate of correct and foil identifications when the perpetrator is present in the lineup (Clark, 2005). One explanation for this increased tendency for a witness to make an identification, regardless of accuracy, is because biased instructions act as an extrinsic accuracy cue implying that the perpetrator is among the lineup members (Leippe et al., 2009). As a result, the witness may lower their criterion for making an identification and identify the most familiar looking lineup member (Brewer \& Wells, 2006).

The impact of biased instructions on identifications may have considerable implications for the results of Study 1. The retrieval cue instructions given to the witnesses could be interpreted as biased given it was not made clear to the participant that the police may have made an error and have an innocent suspect in custody. As a result, witnesses may consider the retrieval cue to be accurate and infer that the other perpetrator must be among the lineup photos presented to them. If this assumption is true, increases in false positive identifications when a witness is given an inaccurate retrieval cue compared to a witness who is given an accurate cue may be the result of the biased instructions and increased choosing behaviour rather than the retrieval cue (i.e., the photo) itself. Therefore it is important to examine this issue using biased and neutral retrieval cue instructions.

\section{Hypotheses}

1.Witness given an accurate retrieval cue with neutral instructions will produce comparable correct identification/correct rejection rates to witnesses given an accurate retrieval cue with biased instructions. 
2. Witnesses given an inaccurate retrieval cue with biased instructions will produce lower correct identification/correct rejection rates than witnesses given an inaccurate retrieval cue with neutral instructions.

3. Witnesses given an inaccurate retrieval cue with neutral instructions will produce comparable correct identification/correct rejection rates to witnesses not given a cue.

\section{Method}

\section{Participants}

A total of three hundred and forty-one $e^{5}\left(238\right.$ women and 103 men) ${ }^{6}$ were recruited via an electronic research participation bulletin board (i.e., the SONA system) at Carleton University in the eastern region of Canada. Participants ranged in age from 17 to 54 years $(M=20.75, S D=4.90)$. Students received course credit for their participation. Twenty-two participants' data could not be used for various reasons. Specifically, three participants expressed knowing an individual in the lineup, 13 participants did not return within the 10-day time limit to complete the study, and 6 participants were removed because of language issues. The participants whose data were removed from analyses on the bases of these issues were relatively evenly distributed across conditions. Analyses were thus conducted on data from the remaining 319 participants ${ }^{7}$.

\section{Design}

A 3 (cue; correct vs. incorrect vs. no cue) x 2 (instructions; neutral vs. bias) $\times 2$

\footnotetext{
${ }^{5}$ One-hundred and eighty-nine of the participants in Study 2 were part of the sample collected and reported Study 1.

${ }^{6}$ No gender differences were found with identification accuracy.

${ }^{7}$ A power analysis was conducted to ensure sufficient ability to detect a difference assuming a small effect.
} 
(lineup; target absent vs. target present) between subjects factorial design was used. The role of the target was counterbalanced across participants such that each of the two confederates assumed the assailant and the accomplice role for half of the conditions.

\section{Stimulus Materials}

Target Video. Same as target video described in Study 1.

Description Form. Same as the description form described in Study 1.

Lineup Construction. Same lineups as described in Study 1.

Lineup Procedure. Same lineup procedure as described in Study 1.

Retrieval Cues. Same retrieval cues as described in Study 1.

Retrieval Cue Instructions. Two sets of retrieval cue instructions were developed. The biased instructions were the same instructions that were provided in Study 1. That is, the biased instructions did not explicitly indicate that the suspect in custody (i.e., the photo cue) may be innocent. Specifically, the biased instructions were:

"The police have apprehended one of the criminals involved in the crime and have this individual in custody."

The neutral instructions explicitly indicated that the suspect in custody may or may not be one of the criminals involved in the crime. Specifically, the neutral instructions were:

"The police have apprehended a suspect who may or may not have been involved in the crime and have this individual in custody."

Deception Awareness Questionnaire. Same questionnaire as described in Study 1.

Perceptions of Retrieval Cue. Same question as described in Study 1.

\section{Procedure}

The same procedure used in Study 1 was followed with minor modifications. 
Specifically, participants in the biased instruction condition were given the biased instructions and the participants in the neutral instruction condition were given the neutral instructions.

\section{Results}

\section{Partitioning Data}

The data were separated into target-present and target-absent data as in Study 1. Moreover, previous research suggests that instruction bias will have differential effects depending on the presence or absence of the target in the lineup (e.g., Charman, 2005; Steblay, 1997).

\section{Preliminary Analyses}

As in Study 1, two confederates were used to play the role of assailant and accomplice. In order to control for differences in identification rates as a result of the confederate, each confederate assumed the assailant and accomplice role in half of the conditions. Moreover, in order to control for differences in identification rates as a result of perpetrator role, the role of the target who was to be identified from the lineup and who was presented as the cue was also counterbalanced across participants. Therefore, in order to collapse the data across target-present or target-absent conditions, confederate, and perpetrator role, it was necessary to determine if there were significant differences in identification accuracy as a function of these variables when the witness was provided with neutral instructions. A number of chi-square analyses were conducted to examine differences in identification accuracy. Preliminary analyses indicated that there were no significant differences between conditions, across confederate, or perpetrator role. See Table 6, 7, and 8 for chi-square results with neutral instructions and Table 9 for 
identification rates as a function of perpetrator and cue accuracy with neutral instructions.

As a result the data were collapsed across target-present or target-absent conditions,

confederate, and perpetrator role for all of the following analyses.

Table 6

Chi-Square Statistic for Comparisons in Identification Accuracy Across all Conditions When Given Neutral Instructions

\begin{tabular}{|c|c|c|c|c|c|c|c|}
\hline & $n$ & $\chi^{2}$ & $p$ & $\phi$ & OR & $\begin{array}{c}\text { Confederate } 1 \\
\text { Correct ID } \\
\end{array}$ & $\begin{array}{c}\text { Confederate } 2 \\
\text { Correct ID } \\
\end{array}$ \\
\hline \multicolumn{8}{|l|}{ Target-present } \\
\hline \multicolumn{8}{|l|}{ Accurate cue $\mathrm{a}^{\mathrm{a}}$} \\
\hline $\begin{array}{l}\text { Identify thief when given } \\
\text { cue of accomplice }\end{array}$ & 16 & 0 & 1.00 & 0 & 1.0 & .25 & .25 \\
\hline $\begin{array}{l}\text { Identify accomplice } \\
\text { when given cue of thief }\end{array}$ & 17 & 0.70 & .40 & .20 & 2.40 & .44 & .25 \\
\hline \multicolumn{8}{|l|}{ Inaccurate cue $^{\mathrm{b}}$} \\
\hline $\begin{array}{l}\text { Identify thief when } \\
\text { given cue of accomplice }\end{array}$ & 16 & 3.69 & .06 & .48 & 0 & 0 & .38 \\
\hline $\begin{array}{l}\text { Identify accomplice } \\
\text { when given cue of thief }\end{array}$ & 16 & 1.00 & .32 & .25 & 2.78 & .63 & .38 \\
\hline \multicolumn{8}{|l|}{ Target-absent } \\
\hline \multicolumn{8}{|l|}{ Accurate cue $^{\mathrm{a}}$} \\
\hline $\begin{array}{l}\text { Identify thief when given } \\
\text { cue of accomplice }\end{array}$ & 16 & 0 & 1.00 & 0 & 1.00 & .38 & .38 \\
\hline $\begin{array}{l}\text { Identify accomplice } \\
\text { when given cue of thief }\end{array}$ & 16 & 0 & 1.00 & 0 & 1.00 & .50 & .50 \\
\hline \multicolumn{8}{|l|}{ Inaccurate cue } \\
\hline $\begin{array}{l}\text { Identify thief when given } \\
\text { cue of accomplice }\end{array}$ & 17 & 0.55 & 46 & .18 & 0.48 & 44 & .63 \\
\hline $\begin{array}{l}\text { Identify accomplice } \\
\text { when given cue of thief }\end{array}$ & 16 & 1.07 & .30 & .26 & 0.33 & .50 & .75 \\
\hline
\end{tabular}

Note. Bonferroni correction for comparisons as a function of target presence in lineup ( $\alpha$ $=.01$ ).

${ }^{a}$ The cue presented was a photo of one of the confederates from the video.

${ }^{b}$ The cue presented was a photo of a similar looking male as one of the confederates from the video. 
Table 7

Chi-Square Statistic for Comparisons in Identification Accuracy of Confederates in each Perpetrator Role Collapsed Across Cue Type and Instruction Type

\begin{tabular}{|c|c|c|c|c|c|c|c|}
\hline & $n$ & $\chi^{2}$ & $p$ & $\phi$ & OR & $\begin{array}{c}\text { Confederate } 1 \\
\text { Correct ID } \\
\end{array}$ & $\begin{array}{c}\text { Confederate } 2 \\
\text { Correct ID } \\
\end{array}$ \\
\hline \multicolumn{8}{|l|}{ Target-present } \\
\hline Thief role & 81 & 0.77 & .38 & .10 & 0.66 & .28 & .37 \\
\hline Accomplice role & 76 & 4.26 & .04 & .24 & 2.69 & .51 & .28 \\
\hline \multicolumn{8}{|l|}{ Target-absent } \\
\hline Thief role & 81 & 0.02 & .90 & .02 & 1.06 & .48 & .46 \\
\hline Accomplice role & 81 & 2.78 & .10 & .19 & 0.47 & .48 & .66 \\
\hline
\end{tabular}

Note. Bonferroni correction for comparisons as a function of target presence in lineup ( $\alpha$ $=.025)$.

Table 8

Chi-Square Statistic for Comparisons in Identification Accuracy of Perpetrator Role Collapsed Across Confederate, Cue Type, and Instruction Type

$\begin{array}{lllllll}n & \chi^{2} & p & \phi & \text { OR } & \text { Thief Correct ID } & \text { Accomplice }\end{array}$

Target-present

$\begin{array}{lllllll}\text { Thief vs. Accomplice } & 157 & 0.93 & .34 & .08 & 0.73 & .32\end{array}$

.39

Target-absent

$\begin{array}{llllll}\text { Thief vs. Accomplice } & 162 & 1.58 & .21 & .10 & 0.67\end{array}$ .47 
Table 9

Identification Decision Rates (n) as a Function of Cue Accuracy and Target Role with Neutral Instructions

Cue Accuracy

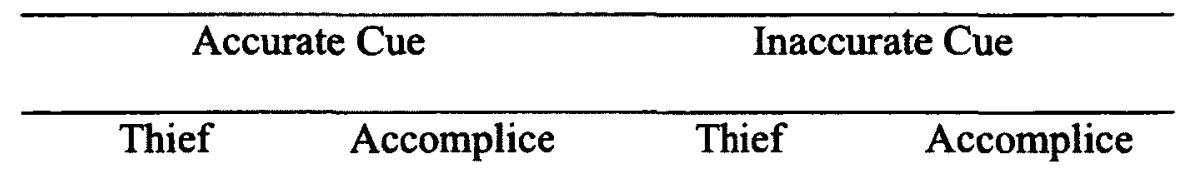

\section{Target-present}

Correct Identification

$.25(4)$

$.35(6)$

$.19(3)$

$.50(8)$

Foil identification

$.38(6)$

$.19(3)$

$.31(5)$

$.13(2)$

False rejection

$.38(6)$

$.45(8)$

$.50(8)$

$.38(6)$

Target-absent

Correct rejection

$.53(9)$

$.63(10)$

*False rejection

$.63(10)$

$.50(8)$

$.47(8)$

$.38(6)$

Note. False positive rate is the rate of identification for all lineup members collapsed in the target-absent condition. 


\section{Target-Present Data}

Cue accuracy and lineup instructions. The specific hypotheses were analyzed using chi-square analyses. See Table 10 for identification accuracy rates as a function of cue accuracy and lineup instructions.

Table 10

Identification Decision Rates (n) as a Function of Cue Accuracy and Instruction Type.

\begin{tabular}{lccccc}
\hline & $\begin{array}{c}\text { Accurate } \\
\text { Cue } \\
\text { Biased } \\
\text { Instructions }\end{array}$ & $\begin{array}{c}\text { Accurate } \\
\text { Cue } \\
\text { Neutral } \\
\text { Instructions }\end{array}$ & $\begin{array}{c}\text { Inaccurate } \\
\text { Cue } \\
\text { Biased } \\
\text { Instructions }\end{array}$ & $\begin{array}{c}\text { Inaccurate } \\
\text { Cue } \\
\text { Neutral } \\
\text { Instructions }\end{array}$ & No Cue \\
Correct identification & $.42(13)$ & $.30(10)$ & $.21(6)$ & $.34(11)$ & $.52(16)$ \\
Foil identification & $.23(7)$ & $.27(9)$ & $.24(7)$ & $.22(7)$ & $.29(9)$ \\
False rejection & $.35(11)$ & $.42(14)$ & $.59(17)$ & $.44(14)$ & $.19(6)$ \\
Target-absent & & & & & \\
Correct rejection & $.59(20)$ & $.44(14)$ & $.53(17)$ & $.58(19)$ & $.45(14)$ \\
*False positive & $.41(14)$ & $.56(18)$ & $.47(15)$ & $.42(14)$ & $.55(17)$ \\
\hline
\end{tabular}

Note. False positive rate is the rate of identification for all lineup members collapsed. 
It was hypothesized that witnesses given an accurate cue with neutral instructions would produce comparable identification rates as witnesses given an accurate cue with biased instructions. Consistent with this hypothesis, witnesses given an accurate cue with neutral instructions produced a comparable correct identification rate as witnesses presented with an accurate cue and given biased instructions $(.30$ vs. .42$), \chi^{2}(1, N=64)=$ $0.94, p=.33, \phi=.12, \mathrm{OR}=0.60$.

It also was hypothesized that witnesses given an inaccurate cue with biased instructions would produce lower correct identification rates than witnesses given an inaccurate cue with neutral instructions. Contrary to this hypothesis, the correct identification rate was comparable across witnesses presented with an inaccurate cue and given biased instructions and witnesses presented with an inaccurate cue and given neutral instructions $(.21$ vs. .34$), \chi^{2}(1, N=62)=1.61, p=.21, \phi=.16, \mathrm{OR}=0.48$ Although not significant, the identification rates do suggest a trend in the hypothesized direction, such that witnesses given an inaccurate cue with neutral instructions were more likely to make a correct identification.

It also was hypothesized that witnesses given an inaccurate cue with neutral instructions would produce comparable correct identification rates to witnesses who were not presented with a cue. Consistent with this hypothesis, the correct identification rate was comparable across witnesses presented with an inaccurate cue and given neutral instructions and witnesses not presented with a cue $(.34$ vs. .52$), \chi^{2}(1, N=63)=1.91, p=$ $.17, \phi=.17, \mathrm{OR}=0.49$

Lineup member choosing rates. In order to determine if the type of instructions accompanying the cue would influence the likelihood that the witnesses would identify a 
lineup member chi-square analyses were completed. Results indicated that witnesses presented with an accurate cue and given biased instructions were equally likely to identify a lineup member (.65) as witnesses presented with an accurate cue and given neutral instructions $(.58), \chi^{2}(1, N=64)=0.32, p=.57, \phi=.07, \mathrm{OR}=1.34$. Similarly, there was no difference in choosing rates between witnesses who were given an inaccurate cue with neutral instructions and witnesses presented with an inaccurate cue with biased instructions, $(.56$ vs. .43$), \chi^{2}(1, N=62)=1.03, p=.31, \phi=.07, \mathrm{OR}=1.68$.

Influence of cue instructions on witness' perception of cue accuracy. In order to determine if the type of instructions accompanying the cue would influence the witness' perceptions regarding the accuracy of the cue presented chi-square analyses were completed. Only participants who provided a definitive answer to this question (i.e., yes or no) were included in the analysis. In the accurate cue condition, two participants were undecided when asked about the accuracy of the cue and four participants failed to answer the question. As a result, data from these six participants were excluded from the analysis. The total $N$ used for this analysis was 58 . In the inaccurate cue condition, two participants were undecided when asked about the accuracy of the cue and two participants failed to answer the question. As a result, data from these four participants were excluded from the analysis. The total $N$ used for this analysis was 58 .

Results indicated that witnesses presented with an accurate cue and given biased instructions were equally likely to perceive the cue as being accurate (.65) as witnesses presented with an accurate cue and given neutral instructions $(.78), \chi^{2}(1, N=58)=1.17, p$ $=.28, \phi=.14, \mathrm{OR}=0.53$. Similarly, witnesses presented with an inaccurate cue and given biased instructions were equally likely to perceive the cue as being inaccurate $(.81)$ 
as witnesses presented with an inaccurate cue and given neutral instructions $(.84), \chi^{2}(1, N$ $=58)=0.58, p=.81, \phi=.03, \mathrm{OR}=0.84$.

\section{Target-absent Data}

Cue accuracy and lineup instructions. The specific hypotheses were analyzed using chi-square analyses. See Table 10 for identification accuracy rates as a function of cue accuracy and lineup instructions.

It was hypothesized that witnesses given an accurate cue with neutral instructions would produce comparable correct rejection rates as witnesses given an accurate cue with biased instructions. Consistent with this hypothesis, witnesses given an accurate cue with neutral instructions produced comparable correct rejection rates as witnesses presented with an accurate cue and given biased instructions (.44 vs. .59$), \chi^{2}(1, N=66)=1.50, p=$ $.22, \phi=.15, \mathrm{OR}=0.54$

It also was hypothesized that witnesses given an inaccurate cue with neutral instructions would produce higher correct rejection rates than witnesses given an inaccurate cue with biased instructions. Contrary to this hypothesis, the correct rejection rate was comparable across witnesses presented with an inaccurate cue and given neutral instructions and witnesses presented with an inaccurate cue and given biased instructions $(.58$ vs. .53$), \chi^{2}(1, N=65)=0.13, p=.72, \phi=.04, \mathrm{OR}=1.20$

It also was hypothesized that witnesses given an inaccurate cue with neutral instructions would produce comparable correct rejection rates to witnesses who were not presented with a cue. Consistent with this hypothesis, the correct rejection rate was comparable across witnesses presented with an inaccurate cue and given neutral instructions and witnesses not presented with a cue $(.58$ vs. .45$), \chi^{2}(1, N=64)=0.99, p=$ 
$.32, \phi=.12, \mathrm{OR}=1.65$.

Influence of cue instructions on witness' perception of cue accuracy. In order to determine if the type of instructions accompanying the cue would influence the witness' perceptions regarding the accuracy of the cue presented chi-square analyses were completed. Only participants who provided a definitive answer to this question (i.e., yes or no) were included in the analysis. In the accurate cue condition, one participant was undecided when asked about the accuracy of the cue and four participants failed to answer the question. As a result, these five participants were excluded from the analysis. The total $N$ used for this analysis was 61 . In the inaccurate cue condition, three participants were undecided when asked about the accuracy of the cue and two participants chose not to answer the question. As a result, data from these five participants were excluded from the analysis. The total $N$ used for this analysis was 60 .

Results indicated that witnesses presented with an accurate cue and given biased instructions were equally likely to perceive the cue as being accurate (.66) as witnesses presented with an accurate cue and given neutral instructions $(.56), \chi^{2}(1, N=61)=0.55, p$ $=.46, \phi=.10, \mathrm{OR}=0.66$. Similarly, witnesses presented with an inaccurate cue and given biased instructions were equally likely to perceive the cue as being inaccurate (.68) as witnesses presented with an inaccurate cue and given neutral instructions $(.66), \chi^{2}(1, N$ $=60)=0.33, p=.86, \phi=.07, \mathrm{OR}=1.09$

\section{Discussion}

The primary objective of Study 2 was to examine if the retrieval cue instructions that accompanied the cue would influence identification accuracy. The retrieval cue instructions provided in Study 1 could be considered biased instructions given the 
instructions imply that the person in custody (i.e., the photo cue) is guilty and therefore, the instructions may act as an additional retrieval cue. Previous research examining lineup instructions suggest that the instructions provided to a witness when presented with an identification task have a large impact on identification accuracy (e.g., Steblay, 1997).

In the present study there is the potential for two retrieval cues to influence memory retrieval; the photo cue and the instruction cue. It is speculated that the "biased" instructions may act as an additional cue creating an expectation that the photo cue is correct. Therefore, when a witness is presented with an inaccurate cue, these instructions may make the witness question their own memory for the perpetrators involved in the crime. As a result, the witness may consider the photo retrieval cue to be accurate and infer that the other perpetrator must be in the lineup since it is unlikely that the police would make an error when they already have correctly apprehended one of the perpetrators. Conversely, the neutral instructions will not act as an additional cue because the instructions do not provide any additional information regarding the photo cue.

It was predicted that witnesses presented with an accurate cue and biased instructions would produce comparable rates of identification accuracy (i.e., correct identifications and correct rejections) as witnesses presented with an accurate cue and neutral instructions. Consistent with this hypothesis there was no difference in accuracy rates between witnesses shown an accurate cue regardless of the instructions that accompanied the cue. This result is consistent with the encoding specificity principle. This principle argues that an accurate cue would facilitate memory retrieval because the 
information relating to that cue was encoded into memory along with the to-beremembered target stimulus resulting in an accurate lineup decision (Thomson \& Tulving, 1970). Thus, it appears that when presented with an accurate cue the instructions that accompany the cue do not have a detrimental effect on accuracy rates.

It also was predicted that witnesses given an inaccurate retrieval cue with neutral instructions would produce higher correct identification/correct rejection rates compared to witnesses given an inaccurate retrieval cue with biased instructions. It was hypothesized that the biased instructions may act as an extrinsic accuracy cue implying that the perpetrator is among the lineup members (Leippe et al., 2009). As a result, the witness may lower their criterion for making an identification and identify the most familiar looking lineup member (Brewer \& Wells, 2006). Conversely, the neutral instructions would not provide any additional information regarding the cue presented to the witness. Thus, the neutral instructions may act to nullify the potential detriment of the inaccurate cue. Contrary to this prediction there was no significant difference in accuracy rates between the two instruction conditions. However, in the target-present condition, correct identification rates do suggest a trend in the predicted direction, such that witnesses presented with an inaccurate cue and given neutral instructions produced a higher correct identification rate compared to witnesses presented with an inaccurate cue and given biased instructions. This trend suggests that the neutral instructions may help to reduce the detrimental effect of the inaccurate visual cue, however, the neutral instructions may not be powerful enough to completely nullify the negative effect of the inaccurate visual cue.

It also was hypothesized that witnesses given an inaccurate cue with neutral 
instructions would produce a comparable correct identification/correct rejection rate as witnesses who were not given a cue. If the neutral instructions do not add any confirmatory information about the visual cue and as such nullify the negative effect of the inaccurate visual cue then identification rates would be similar to witnesses who were not presented with a visual cue. Consistent with this prediction, there was no difference in correct identification/correct rejection rates across the two conditions. This suggests that the neutral instructions may help to reduce the detrimental effect of the inaccurate visual cue.

Interestingly, instructions were not found to influence overall choosing rates of the witnesses in the target-present condition. Previous research has found that providing biased instructions at the time of a lineup identification task results in an increase in choosing behaviour (e.g., Steblay, 1997). This result was not supported by the current data. It is possible that the instructions did not have the same influence on choosing behaviour because the biased instructions that accompanied the visual cue were overpowered by the neutral lineup instructions that were provided to all the witnesses at the time of the lineup identification task. As a result, the instructions that accompanied the visual cue may have provided information about the cue to the witness regarding the accuracy or inaccuracy of the photo presented. However, when presented with the lineup identification task, the witness may have relied on the instructions provided at that time when making their lineup decision.

It also was interesting that the instructions provided to the witness did not influence their perceptions of the visual cue's accuracy. If the biased instructions were providing additional information to the witness regarding the accuracy of the cue 
presented it would be expected that the witnesses who received the biased instructions would be more likely to perceive the cue as being accurate compared to witnesses who were given neutral instructions. This was not the case. Witnesses given neutral instructions perceived the cue as being accurate/inaccurate at comparable rates. In order to prevent confounds within the experiment, witnesses were asked to render a decision regarding their perception of the accuracy/inaccuracy of the visual cue at the end of the experiment. Therefore, there is the potential that the witness may not be accurate in their reporting of their perceptions of their memory.

Taken together, these results suggest that the neutral instructions may help to reduce the detrimental effect of the inaccurate cue, however it does not appear that the neutral instructions are powerful enough to completely nullify the potential negative effect of the inaccurate cue. Moreover, it appears that the neutral instructions function somewhat differently from the instructions that are provided during a lineup identification task. 


\section{General Discussion}

The purpose of the present two studies was to investigate the use of a retrieval cue as a way to facilitate recognition of a perpetrator involved in a multiple perpetrator crime. The primary goal of this dissertation was to examine the effect of a visual image (i.e., photo) as an effective retrieval cue for identification accuracy. The retrieval cue in this study was a photo of one of the perpetrators involved in a two-perpetrator crime. The encoding specificity principle suggests that a cue will be effective when it is encoded in reference to the to-be-remembered stimulus (Thomson \& Tulving, 1970). Presumably, a photo of one of the perpetrators involved in the crime would act as a recollective cue, thus increasing the likelihood the witness would correctly recognize the other perpetrator who was involved. Thus, it was hypothesized that witnesses given an accurate retrieval cue at the time of the lineup identification task would be more accurate than witnesses given no cue or an inaccurate cue. Results from Study 1 indicated that witnesses presented with an inaccurate cue had marginally lower correct identification rates compared to witnesses presented with an accurate cue in the target-present condition. However, there was no difference in correct rejection rates. This finding is consistent with previous research investigating context reinstatement (i.e., faces that accompany the target face during the encoding phase). Research in this area has found that facial recognition is facilitated when the context during the test phase matches the context during the study phase, that is the same faces are presented together during study and test and is impaired when the context is inconsistent with the study phase (e.g., Bower \& Karlin, 1974; Watkins et al., 1976; Winograd \& Rivers-Bulkeley, 1977).

Surprisingly, there was no difference in correct identification or correct rejection 
rates between witnesses presented with an accurate cue and witnesses not shown a cue. This finding is inconsistent with previous research investigating the use of paired-faces in facial recognition studies. Previous facial recognition literature indicates substantial decreases in accuracy rates when context is deleted during the test phase (i.e., the face was presented alone; Winograd \& Rivers-Bulkeley, 1977). This is the first study to examine this phenomenon (i.e., using a facial visual cue) using an eyewitness paradigm. This research is important in that it suggests that context or cues may function very differently when presented in an applied context. Moreover, these results raise further concerns regarding the formulation of eyewitness predictions based on the facial recognition literature (e.g., Pozzulo \& Lindsay, 1998).

Previous research has been completed using cues as a means to facilitate identification using an eyewitness paradigm (e.g., Cutler et al., 1986; Davies \& Milne, 1985; Malpass \& Devine, 1981a; Sanders, 1984; Sporer, 2007). Overall, consistent with the findings of Study 1 , contextual cues that were accurate or consistent with the information that was originally encoded, had a small (not always significant) positive effect on facial recognition. Conversely, inaccurate or inconsistent contextual cues were found to be detrimental and reduced accuracy (e.g., Cutler et al., 1986; Sporer, 2007). However, the studies that investigated this phenomenon often combined several different cues in the same study and as a result it was difficult to determine which, if any of the context cues, had an effect or in what combination. The present studies went to great lengths to control for any possible overlapping or confounding variables. For instance, all conditions were counterbalanced to control for any differences due to confederate or perpetrator role. A one-week delay also was implemented to control for any potential 
verbal overshadowing effects (i.e., impaired recognition performance as a result of verbalizing the appearance of a previously seen visual stimuli; Schooler \& EngstlerSchooler, 1990) that may arise from providing a free-recall description of the perpetrators prior to completing a lineup identification. Moreover, in order to control for possible environmental cues, witnesses completed the lineup identification task in a different room from where they originally witnessed the crime. This methodological design allows for more confident conclusions that the facial cue that was provided was responsible for the observed effects. The other benefit to the current research is the forensic utility of the type of cue that was utilized. Previous studies exploring the use of context reinstatement cues using an eyewitness paradigm have been criticized for the little forensic utility of the cue in a real world setting (Cutler et al., 1986). The cue utilized in the present studies has high forensic utility because in a situation involving multiple perpetrators in that, it is very possible that one perpetrator might be apprehended while the other is still at large. Thus, providing a photo of one of the perpetrators is an option law enforcement and has been used in real-life investigations.

A second goal of this dissertation was to examine the influence of instruction bias and retrieval cue on identification accuracy. The retrieval cue instructions provided in Study 1 could be considered biased instructions given the instructions imply that the person in custody (i.e., the photo cue) is guilty and therefore the instructions may act as an additional retrieval cue. It was hypothesized that biased instructions accompanying an inaccurate cue would result in more identification errors. Results from Study 2 indicated a trend in the predicted direction such that neutral instructions may help to nullify the detrimental effect of presenting an inaccurate cue to a witness. Interestingly, instructions 
were not found to influence overall choosing rates of the witnesses in the target-present condition. Previous research has found that providing biased instructions at the time of a lineup identification task results in an increase in choosing behaviour (e.g., Steblay, 1997). However, it is important to note that at the time of the lineup identification all witnesses received neutral lineup instructions. Therefore, it is possible that the instructions that accompanied the cue were not considered when the witness was making their lineup decision and as a result the cue instructions did not impact choosing rates. Thus, it appears that the neutral instructions function somewhat differently from the instructions that are provided during a lineup identification task. Overall, these results suggest that the neutral instructions may help to reduce the detrimental effect of the inaccurate cue, however it does not appear that the neutral instructions are powerful enough to completely nullify the potential negative effect of the inaccurate cue.

Results from both studies also serve to further the research investigating identification accuracy of multiple perpetrators. Overall performance on the identification task for both studies was low, producing a mean accuracy rate of .36. This rate suggests that the identification of a perpetrator involved in a multiple perpetrator crime may be more difficult than identifying a perpetrator involved in a single perpetrator crime. Typical lineup identification accuracy rates tend to range from $70-75 \%$ (Pozzulo \& Lindsay, 1998). This lower identification rate is similar those found in other studies examining the identification accuracy of perpetrators involved in a multiple perpetrator crime. This provides further support for the notion that accuracy rates are impaired when more than one perpetrator is involved in the crime (Clifford \& Hollin, 1981; Shapiro \& Penrod, 1986; Wells \& Pozzulo, 2006). 
Interestingly, in the present studies there was no difference in accuracy rates depending on the role that the individual had in the commission of the offence (i.e., the thief vs. the accomplice). Research examining differences in identification of these two roles is mixed. Some studies have found that witnesses were more likely to correctly identify the accomplice rather than the assailant in a two-perpetrator crime (Geisleman et al., 1993; Wells \& Pozzulo, 2006). However, other research suggests that a witness may be more likely to identify the assailant rather than the accomplice (Christianson \& Loftus, 1987; Dempsey \& Pozzulo, 2008). It is possible that these disparate results may be the result of methodological issues regarding the stimulus materials that were used in these studies (Dempsey \& Pozzulo, 2008). In the two studies that found that the accomplice was more likely to be correctly identified compared to the assailant, there was a substantial difference in target exposure (Dempsey \& Pozzulo, 2008). For instance, the accomplice was the only target to have any spoken lines during the commission of the offence. As a result, it is possible that the difference in accuracy rates may be a result of the accomplice being the only individual to have spoken during the commission of the offence. As mentioned previously, the current study attempted to address these confounds by controlling for target exposure. Both perpetrators had equal exposure time and neither had any spoken lines. These results suggest that holding all things constant there is no difference in accuracy rates as a function of perpetrator role. However, more research using stimuli that controls for these differences is crucial. Perhaps, holding all other variables constant, identification rates become a function of the number of perpetrators involved. Understanding if and under what conditions a witness may be more likely to correctly identify one perpetrator over another as a function of the role 
they played during the commission of the crime is critical when one considers the different legal implications available to each individual depending on their involvement in the crime.

Overall, the present data do not support the use of recollective cues as a means to facilitate recognition of a perpetrator involved in a multiple perpetrator crime. Providing an accurate cue of one of the perpetrators involved in the crime did not produce significantly higher correct identification or correct rejection rates compared to witnesses who were not shown a cue. However, providing an inaccurate visual cue to a witness produced an increase in identification errors. Moreover, providing neutral instructions did not appear to be sufficient to eliminate the detrimental effect of the inaccurate cue. In real-world applications there is no definitive way of knowing whether the cue that is provided to a witness is accurate or inaccurate. Thus, the risk associated with potentially providing a witness with an inaccurate cue outweighs any potential gain (if any) that would be associated with providing a witness with an accurate cue.

\section{Limitations and Future Directions}

One limitation to the present study concerns the ecological validity of laboratory research on eyewitness memory. The present studies utilized a videotaped simulation of a crime. The use of videotaped crime simulations have been criticized for a number of reasons. For instance, this mode of target exposure has been criticized for not replicating the same degree of emotional arousal and personal threat that one would experience as a witness to a real-life crime event (Penrod, Fulero, \& Cutler, 1995). Moreover, videotaped exposure provides a uniform view of the crime event where the witness is a passive viewer. One method used in an attempt to replicate a more real-life crime event 
is to use an innocuous live crime simulation. Live crime simulations provide a closer replication of a real-world event including the potential for similar arousal levels and viewing of the perpetrator(s). In order to explore the generalizability of the current findings, further research is required using different methods of target exposure.

A second limitation of these studies is that only one type of cue was explored. The present studies utilized a picture of one of the perpetrators involved in the crime as a means to facilitate the recognition of the other individual involved in the crime. It is important to note that the cue utilized in these studies was a human face. Therefore, there is the potential for cognitive interference for the recognition of a subsequent face (McAllister, 2007). In order to prevent the possibility of cognitive interference a different type of pictorial cue could be utilized, such as a picture of a piece of clothing that was worn during the commission of the offence. Previous research examining the use of verbal cues, such as having a witness re-read their description of the perpetrator has not yielded positive results (e.g., Sporer, 2007). These results suggest that verbal cues may not be effective because they may utilize a different part of memory (i.e., recall memory) rather than recognition memory which is what is required for a lineup identification task. Therefore, future research should explore the use of other pictorial cues as a means to facilitate recognition in single and multiple perpetrator crimes. For instance, a piece of clothing that the suspect was wearing during the commission of the offence could be presented.

It is also important for future research to explore common variables present in multiple perpetrator crime and how these variables influence eyewitness identification accuracy. For instance, future research should examine how the number of perpetrators 
involved in the crime may influence identification accuracy. Previous research suggests that as the number of perpetrators involved in a crime increases, identification accuracy decreases (Clifford \& hollin, 1981; Shapiro \& Penrod, 1986, Wells \& Pozzulo, 2006). However, at present it is unknown if there is a maximum number of perpetrators that can be encoded before a witness is not able to identify any of the perpetrators.

Similarity of the perpetrators may also affect a witness' ability to accurately identify the individuals involved in the commission of an offence. Many of the multiple perpetrator crimes that occur are gang-related (Statistics Canada, 2001). Individuals with gang affiliations may dress in a similar way to denote their association with the given group. Moreover, these individuals may also be similar in age and ethnicity. As a result, the individuals involved in the commission of the crime may look very similar, limiting the number of distinctive features that a witness may use to later distinguish and recognize the individuals involved. It is also unclear how the presence of a weapon may further complicate the identification of multiple perpetrators. Previous research examining the effect of the presence of a weapon during the course of a single-perpetrator crime has indicated a significant reduction in identification accuracy (Steblay, 1992). Currently, there is no research examining the effect of the presence of a weapon during the commission of an offence involving multiple perpetrators. Given the frequency with which multiple perpetrator crimes occur further research in this area is imperative.

\section{Implications}

Crimes involving multiple perpetrators provide law enforcement with a unique situation in that, it is possible that one suspect may be apprehended in relation to a crime while other suspects remain at large. Given that the police have an individual in custody, 
it is possible to use this individual as a cue to help facilitate the memory of witnesses to the crime in order to apprehend the remaining criminals. Police may then arrange for the witness to see the individual in custody or provide a photo of the individual in custody as a memory aid to the witness. Based on the present findings, exposing the witness to this cue may hinder the witnesses' subsequent recognition for the other individuals involved, especially if the person in custody is not the guilty perpetrator.

Moreover, many media outlets including television news and daily newspapers provide pictures to the community of individuals who have been arrested in association with a crime where other suspects still remain at large. These instances are especially true for crimes committed by multiple perpetrators, especially crimes committed by gang members. Often time these news releases end with a request for help from the public in identifying the suspects who are still at large in the community. Given the results of the present studies, providing a picture of one of the perpetrators may be detrimental. An individual who had witnessed the crime or who may have information regarding the crime in question may become more cautious or second-guess their memory of the event if the picture presented did not match their memory. As a result, the witness may be too reluctant to come forward with important details related to the crime. Overall, the results from the present studies would suggest that police and media outlets should refrain from providing photos of individuals in custody while searching for the other individuals involved in the crime in question.

\section{Conclusions}

In conclusion, the results from the present two studies do not provide support for the use of retrieval cues as a method for improving identification accuracy of multiple 
perpetrators. Providing an accurate cue of one of the individuals involved in the crime did not produce higher accuracy rates compared to participants who were not given a cue; whereas, providing an inaccurate cue did result in more errors. Moreover, providing neutral instructions with the cue did not nullify the detrimental effects of the inaccurate cue. Further research examining methods for improving identification accuracy of multiple perpetrators is needed. 


\section{References}

Anderson, J. R., \& Bower, G. H. (1972). Recognition and retrieval processes in free recall. Psychological Review, 79, 97-123. doi:10.1037/h0033773

Ashcraft, M. H. (2006). Cognition. New Jersey: Pearson Prentice Hall.

Atkinson, R. C., \& Shiffrin, R. M. (1968). Human memory: A proposed system and its control processes. In K. W. Spence, \& J. T. Spence (Eds.), The psychology of learning and motivation: Advances in research and theory, Volume 2. New York: Academic Press.

Atkinson, R. C., \& Shiffrin, R. M. (1969). Storage and retrieval processes in long-term memory. Psychological Review, 76, 179-193. doi:10.1037/h0027277

Baddeley, A. (1992). Working memory. Science, 255, 556-559. doi: $10.1126 /$ science. 1736359

Baddeley, A. D. (1999). Essentials of Human Memory. England: Psychology Press. Beales, S. A., \& Parkin, A. J. (1984). Context and facial memory: The influence of different processing strategies. Human Learning, 3, 257-264.

Biederman, I. (1972). Perceiving Real World Scenes. Science, 177, 77-80. doi:10.1126/science.177.4043.77

Biederman, I., Glass, A. I., \& Stacey, E. W. (1973). Searching of objects in real world scenes. Journal of Experimental Psychology, 97, 22-27. doi:10.1037/h0033776

Bower, G. H., \& Karlin, M. B. (1974). Depth of processing, pictures of faces and recognition memory. Journal of Experimental Psychology, 103, 751-757. doi: $10.1037 / \mathrm{h} 0037190$ 
Brigham, J. C., Ready, D. J., \& Spier, S. A. (1990). Standards for evaluating the faimess of photograph lineups. Basic and Applied Social Psychology, 11, 149-163. doi: 10.1207/s15324834basp1102_3

Brewer, N., \& Wells. G. L. (2006). The confidence-accuracy relationship in eyewitness identification: Effects of lineup instructions, foil similarity, and target-absent base rates. Journal of Experimental Psychology: Applied, 12, 11-30. doi:10.1037/1076898X.12.1.11

Bruce, V. G. (1979). Searching for politicians: An information processing approach to face recognition. Quarterley Journal of Experimental Psychology, 31, 373-395. doi: $10.1080 / 14640747908400734$

Bureau of Justice Statistics (2007). Homicide trends in the United States. Retrieved 9 September 2007 from http://www.ojp.usdoj.gov/bjs/homicide/multiple.htm

Chance, J. E., \& Goldstein, A. G. (1984). Face-recognition memory: Implications for children's eyewitness testimony. Journal of Social Issues, 40, 69-85.

Christianson, S., \& Loftus, E. F. (1987). Memory for traumatic events. Applied Cognitive Psychology, 1, 225-239. doi:10.1002/acp.2350010402

Clark, S. E. (2005). A re-examination of the effects of biased lineup instructions in eyewitness identification. Law and Human Behavior, 29, 575-604. doi:10.1007/s10979-005-7121-1

Clifford, B. R. \& Hollin, C. R. (1981). Effects of the type of incident and the number of perpetrators of eyewitness memory. Journal of Applied Psychology, 66, 364-370. doi:10.1037/0021-9010.66.3.364 
Cohen, G. (1996). Memory in the Real World. Hove, England: Lawrence Erlbaum Associates, $2^{\text {nd }}$ Edition.

Cutler, B. L., \& Penrod, S. D. (1988). Improving the reliability of eyewitness identification: Lineup construction and presentation. Journal of Applied Psychology, 73, 281-290. doi:10.1037/0021-9010.73.2.281

Cutler, B. L., Penrod, S. D., O'Rourke, T. E., \& Martens, T. K. (1986). Unconfounding the effects of contextual cues on eyewitness identification accuracy. Social Behaviour, 1, 113-134.

Cutler, B. L., Penrod, S. D., \& Martens, T. K. (1987). Improving the reliability of eyewitness identification: Putting context into context. Journal of Applied Psychology, 72, 629-637. doi:10.1037/0021-9010.72.4.629

Davies, G., \& Milne, A (1982). Recognizing faces in and out of context. Current Psychological Research, 2, 235-246. doi:10.1007/BF02684516

Davies, G. \& Milne, A. (1985). Eyewitness composite production: A function of mental or physical reinstatement of context. Criminal Justice and Behavior, 12, 209-220. doi:10.1177/0093854885012002004

Dempsey, J. L. \& Pozzulo, J. D. (2008). Identification accuracy of eyewitnesses for a multiple perpetrator crime: Examining the simultaneous and elimination lineup procedures. American Journal of Forensic Psychology, 26, 1-16. doi: $10.1177 / 0093854885012002004$

Dysart, J. E., Lindsay, R. C. L., \& Dupuis, P. R. (2006). Show-ups: The critical issue of clothing bias. Applied Cognitive Psychology, 20, 1009-1023. doi:10.1002/acp.1241 
Freire, A., Lee, K., Williamson, K. S., Lindsay, R. C. L., \& Stuart, S. J. E. (2004).

Lineup identification by children: Effects of clothing bias. Law and Human Behavior, 28, 339-354. doi:10.1023/B:LAHU.0000029142.00834.e3

Geiselman, E. R., MacArthur, A., \& Meerovitch, S. (1993). Transference of perpetrator roles in eyewitness identifications from photoarrays. American Journal of Forensic Psychology, 11, 5-15.

Geiselman, R. E., Fisher, R. P., Hutton, L. A., Sullivan, S., Avetission, I. V., \& Frosk, A. L. (1984). Enhancement of eyewitness memory: An empirical evaluation of a cognitive interview. Journal of Police Science and Administration, 12, 74-80.

Groeger, J. A. (1997). Memory and Remembering: Everyday Memory in Context. New York, NY: Addison Wesley Longman Inc.

Kneller, W., Memon, A., \& Stevenage, S. (2001). Simultaneous and sequential lineups: Decision processes of accurate and inaccurate eyewitnesses. Applied Cognitive Psychology, 15, 659-671. doi:10.1002/acp.739

Landauer, T. K. (1986). How much do people remember? Some estimates of the quantity of learned information in long-term memory. Cognitive Science: $A$ Multidisciplinary Journal, 10, 477-493.

Leippe, M. R., Eisenstadt, D., \& Rauch, S. M. (2009). Cueing confidence in eyewitness identifications: Influence of biased lineup instructions and pre-identification memory feedback under varying lineup conditions. Law and Human Behavior, 33, 194-212. doi:10.1007/s10979-008-9135-y

Levi, A. M. (2007). Research note: Evidence for moving to an 84-person photo lineup. Journal of Experimental Criminology, 3, 377-391. doi:10.1007/s11292-007-9042-0 
Levine, F. J., \& Tapp, J. L. (1973). The psychology of criminal identification: The gap from Wade to Kirby. University of Pennsylvania Law Review, 121, 1079-1131.

Lindsay, R. C. L., \& Bellinger, K. (1999). Alternatives to the sequential lineup: The importance of controlling the pictures. Journal of Applied Psychology, 84, 315321. doi:10.1037/0021-9010.84.3.315

Lindsay, R. C. L., Lea, J. A., Nosworthy, G. J., Fulford, J. A., Hector, J., LeVan, V., Seabrook, C. (1991). Biased lineups: Sequential presentation reduces the problem. Journal of Applied Psychology, 76, 796-802. doi:10.1037/0021-9010.76.6.796

Lindsay, R. C. L., Wallbridge, H., \& Drennan, D. (1987). Do the clothes make the man? An exploration of the effect of lineup attire on eyewitness identification accuracy. Canadian Journal of Behavioural Science, 19, 463-478. doi:10.1037/h0079998

Lindsay, R. C. L., \& Wells, G. L. (1985). Improving eyewitness identifications from lineups: Simultaneous versus sequential lineup presentation. Journal of Applied Psychology, 70, 556-564. doi:10.1037/0021-9010.70.3.556

Loftus, E., Manber, M., \& Keating, J. P. (1983). Recollection of naturalistic events: Context enhancement vs. negative cuing. Human Learning, 2, 83-92.

Luus, C. E., \& Wells, G. L. (1991). Eyewitness identification and the selection of distracters for lineups. Law and Human Behavior, 15, 43-57. doi:10.1007/BF01044829

Malpass, R. S. (1981). Effective size and defendant bias in eyewitness identification lineups. Law and Human Behavior, 5, 299-309. doi:10.1007/BF01044945 
Malpass, R. S. (1996). Enhancing eyewitness memory. In S. L. Sporer, R. S. Malpass, \& G. Koehneken (Eds.), Psychological issues in eyewitness identification (pp. 177204). Hillsdale, NJ: Lawrence Erlbaum Associates, Inc.

Malpass, R. S. \& Devine, P. G. (1981a). Guided memory in eyewitness identification. Journal of Applied Psychology, 66, 343-350. doi:10.1037/0021-9010.66.3.343

Malpass, R. S., \& Devine, P. G. (1981b). Eyewitness identification: Lineup instructions and the absence of the offender. Journal of Applied Psychology, 66, 482-489. doi:10.1037/0021-9010.66.4.482

Malpass, R. S., \& Devine, P. G. (1983). Measuring lineup fairness of eyewitness identification lineups. In S. M. A. Lloyd-Bostock \& B. R. Clifford (Eds.), Evaluating witness evidence (pp. 81-102). New York: Wiley.

Malpass, R. S., Tredoux, C. G., \& McQuiston-Surrett, D. (2007). Lineup construction and lineup faimess. In R. C. L. Lindsay, D. F. Ross, J. D. Read, \& M. P. Toglia (Eds.), The handbook of eyewitness psychology Vol. II: Memory for people (pp. 155-178). Mahwah, NJ: Lawrence Erlbaum Associate Publishers.

McAllister, H. A. (2007). Mug books: More than just large photospreads. In R. C. L. Lindsay, D. F. Ross, J. D. Read, \& M. P. Toglia (Eds.), The handbook of eyewitness psychology Vol. II: Memory for people (pp. 35-58). Mahwah, NJ: Lawrence Erlbaum Associate Publishers.

McQuiston-Surrett, D., Malpass, R. S., \& Tredoux, C. G. (2006). Sequential vs. simultaneous lineups: A review of methods, data, and theory. Psychology, Public Policy, and Law, 12, 137-169. doi:10.1037/1076-8971.12.2.137 
Megreya, A. M. \& Burton, A. M. (2006). Recognising faces seen alone or with others: When two heads are worse than one. Applied Cognitive Psychology, 20, 957-972. doi:10.1002/acp.1243

Melara, R. D., DeWitt-Rickards, T. S., \& O’Brien, T. P. (1989). Enhancing lineup identification accuracy: Two codes are better than one. Journal of Applied Psychology, 74, 706-713. doi:10.1037/0021-9010.74.5.706

Memon, A. \& Bruce, V. (1985). Context effects in episodic studies of verbal and facial memory: A review. Current Psychological Research and Reviews, Winter, 349369. doi:10.1007/BF02686589

Meyer, D. E., \& Schvaneveldt, R. W. (1976). Meaning, memory structures and mental processes. Science, 192, 27-33. doi:10.1126/science.1257753

Miller, G. A. (1956). The magical number seven, plus or minus two: Some limits on our capacity for processing information. Psychological Reviews, 63, 81-97. doi: $10.1037 / \mathrm{h} 0043158$

Nilsson, L., \& Larsson, M. (2007). Self-referent beliefs about memory and actual performance: Relationships with age and sex. In S. Magnussen, \& T. Helstrup (Eds.), Everyday memory (pp. 275-289). New York, NY: Psychology Press.

Nosworthy, G. J., \& Lindsay, R. C. (1990). Does nominal size matter? Journal of Applied Psychology, 75, 358-361. doi:10.1037/0021-9010.75.3.358

Palmer, S. E. (1975). The effects of contextual scences on the identification of objects. Memory \& Cognition, 3, 519-526. 
Parkin, A. J., \& Hayward, C. O. (1983). The influence of trait and physical features based orienting strategies on aspects of facial memory. British Journal of Psychology, 74, 71-82. doi:10.1111/j.2044-8295.1983.tb01844.x

Penrod, S. D., Fulero, S. M., \& Cutler, B. L. (1995). Expert psychological testimony on eyewitness reliability before and after Daubert: The state of the law and the science. Behavioral Sciences and the Law, 13, 229-260.

Pozzulo, J. D., \& Lindsay, R. C. L. (1998). Identification accuracy of children versus adults: A meta-analysis. Law and Human Behavior, 22, 549-570. doi:10.1023/A:1025739514042

Pozzulo, J. D., \& Lindsay, R. C. L. (1999). Elimination lineups: An improved identification procedures for child eyewitnesses. Journal of Applied Psychology, 84, 167-176. doi:10.1037/0021-9010.84.2.167

Pryke, S., Lindsay, R. C. L., Dysart, J. E., \& Dupuis, P. (2004). Multiple independent identification decisions: A method of calibrating eyewitness identifications. Journal of Applied Psychology, 89, 73-84. doi:10.1037/0021-9010.89.1.73

Reicher, G. M. (1969). Perceptual recognition as a function of meaningfulness of stimulus materials. Journal of Experimental Psychology, 81, 275-280. doi: $10.1037 / \mathrm{h} 0027768$

Roediger, H. L., III, \& Guynn, M. J. (1996). Retrieval processes. In E. L. Bjork, \& R. A. Bjork (Eds.), Memory. Handbook of perception and cognition, $2^{\text {nd }}$ Edition (pp. $197-$ 236). San Diego, CA: Academic Press. doi:10.1016/B978-012102570-0/50009-4 
Sanders, G. S. (1984). Effects of context cues on eyewitness identification responses. Journal of Applied Social Psychology, 14, 386-397. doi:10.1111/j.15591816.1984.tb02246.x

Shapiro, P. N. \& Penrod, S. (1986). Meta-analysis of facial identification studies. Psychological Bulletin, 100, 139-156. doi:10.1037/0033-2909.100.2.139

Sporer, S. L. (1993). Eyewitness identification accuracy, confidence, and decision times in simultaneous and sequential lineups. Journal of Applied Psychology, 78, 22-33. doi: $10.1037 / 0021-9010.78 .1 .22$

Sporer, S. L. (2007). Person descriptions as retrieval cues: Do they really help? Psychology, Crime, \& Law, 13, 591-609. doi:10.1080/10683160701253986

Standing, L. (1973). Learning 10, 000 Pictures. The Quarterly Journal of Experimental Psychology, 25, 207-222. doi:10.1080/14640747308400340

Statistics Canada (2001). Retrieved 9 September 2007 from http:/www.statcan.ca/bsolc/english/bsolc? catno $=85 F 0033 \mathrm{M2001005.htm}$ Statistics Canada (2008). Retrieved 15 July 2009 from http://www.statcan.gc.ca/dailyquotidien/080516/dq080516.a-eng.htm

Steblay, N. K. (1997). Social influence in eyewitness recall: A meta-analytic review of lineup instruction bias. Law and Human Behavior, 21, 283-297. doi:10.1023/A:1024890732059

Steblay, N. K., Dysart, J. E., Fulero, S., \& Lindsay, R. C. L. (2001). Eyewitness accuracy rates in sequential and simultaneous lineup presentations: A meta-analytic comparison. Law and Human Behavior, 25, 459-473.

doi:10.1023/A:1012888715007 
Steblay, N. K., Dysart, J. E., \& Wells, G. L. (2011). Seventy-two tests of the sequential lineup superiority effect: A meta-analysis and Policy Discussion. Psychology, Public Policy, and Law, 7, 99-139. doi:10.1037/a0021650

Thomson, D. M. (1981). Person identification: Influencing the outcome. Australian and New Zealand Journal of Criminology, 14, 49-54.

Thomson, D. M. (1988). Context and false recognition. In G. M. Davies, \& D. M. Thomson, Memory in context: Context in memory (pp. 285-304). Oxford, England: John Wiley \& Sons.

Thompson, R. F., \& Madigan, S. A. (2005). Memory: The key to consciousness. Princeton, NJ: Princeton University Press.

Thomson, D. M., Roberston, S. L., \& Vogt, R. (1982). Person recognition: The effect of context. Human Learning, 1, 137-154.

Thomson, D. M. \& Tulving, E. (1970). Associative encoding and retrieval: Weak and strong cues. Journal of Experimental Psychology, 86, 255-262.

doi: $10.1037 / \mathrm{h} 0029997$

Tulving, E. (1972). Episodic and semantic memory. In W. Donaldson (Ed.). Organization of memory. New York, NY: Academic Press.

Tulving, E. (1983). Elements of episodic memory. London: Oxford University Press.

Tulving, E. (1985). How many memory systems are there? American Psychologist, 40, 385-398. doi:10.1037/0003-066X.40.4.385

Tulving E. (1986). Episodic and semantic memory: Where should we go from here? Behavioral and Brain Sciences, 9, 573-577. doi:10.1017/S0140525X00047257 
Tulving, E. (1993). What is episodic memory? Current Directions in Psychological Science, 2, 67-70. doi:10.1111/1467-8721.ep10770899

Tulving, E. (2002). Episodic memory: From mind to brain. Annual Review of Psychology, 53, 1-25. doi:10.1146/annurev.psych.53.100901.135114

Tulving, E., \& Gold, C. (1963). Stimulus information and contextual information as determinants of tachistoscopic recognition of words. Journal of Experimental Psychology, 66, 319-327. doi:10.1037/h0048802

Tulving, E., \& Pearlstone, Z. (1966). Availability versus accessibility of information in memory for words. Journal of Verbal Learning and Verbal Behaviour, 5, 381-391. doi: $10.1016 / \mathrm{S} 0022-5371(66) 80048-8$

Tunnicliff, J. L., \& Clark, S. E. (2000). Selecting foils for identification lineups: Matching suspects or descriptions? Law and Human Behavior, 24, 231-258. doi:10.1023/A:1005463020252

Wagstaff, G. F. (1982). Hypnosis and recognition of a face. Perceptual and Motor Skills, 55, 816-818.

Wall, P. M. (1965). Eyewitness Identification in Criminal Cases. Springfield, Illinois: Charles C. Thomas.

Watkins, M. J., Ho, E., \& Tulving, E. (1976). Context effects in recognition memory for faces. Journal of Verbal Learning and Verbal Behavior, 15, 505-517. doi: $10.1016 / 0022-5371(76) 90045-1$

Weiten, W., \& McCann, D. (2007). Psychology: Themes and Variations, First Canadian Edition. Toronto, ON: Nelson Education Ltd. 
Wells, E. C. \& Pozzulo, J. D. (2006). Accuracy of eyewitnesses with a two-culprit crime: Testing a new identification procedure. Psychology, Crime \& Law, 12, 417-427. doi: $10.1080 / 10683160500050666$

Wells, G. L. (1993). What do we know about eyewitness identification? American Psychologist, 48, 553-571. doi:10.1037/0003-066X.48.5.553

Wells, G. L., \& Lindsay, R. C. L. (1980). On estimating the diagnosticity of eyewitness nonidentifications. Psychological Bulletin, 88, 776-786. doi:10.1037/00332909.88.3.776

Wells, G. L., \& Luus, C. E. (1990). The diagnosticity of a lineup should not be confused with the diagnostic value of nonlineup evidence. Journal of Applied Psychology, 75, 511-516. doi:10.1037/0021-9010.75.5.511

Wells, G. L., Malpass, R. S., Lindsay, R. C. L., Fisher, R. P., Turtle, J. W., \& Fulero, S. M. (2000). From the lab to the police station: A successful application of eyewitness research. American Psychologist, 55, 581-598. doi:10.1037/0003066X.55.6.581

Wells, G. L., Memon, A., \& Penrod, S. D. (2006). Eyewitness evidence: Improving its probative value. Psychological Science in the Public Interest, 7, 45-75. doi:10.1111/j.1529-1006.2006.00027.x

Wells, G. L., Rydell, S. M., \& Seelau, E. P. (1993). The selection of distractors for eyewitness lineups. Journal of Applied Psychology, 78, 835-844. doi:10.1037/0021-9010.78.5.835

Wells, G. L., Seelau, E. P., Rydell, S. M., \& Luus, C. E. (1994). Recommendations for properly conducted lineup identification tasks. In D. F. Ross, J. D. Read, \& M. P. 
Toglia, Adult eyewitness testimony: Current trends and developments (pp. 223244). New York, NY: Cambridge University Press.

Wells, G. L., Small, M., Penrod, S., Malpass, R. S., Fulero, S. M., \& Brimacombe, C. A. E. (1998). Eyewitness identification procedures: Recommendations for lineups and photospreads. Law and Human Behavior, 22, 603-647.

doi:10.1023/A:1025750605807

Wells, G. L., \& Turtle, J. W. (1986). Eyewitness identification: The importance of lineup models. Psychological Bulletin, 99, 320-329. doi:10.1037/0033-2909.99.3.320

Wheeler, D. D. (1970). Process in word recognition. Cognitive Psychology, 1, 59-85. doi:10.1016/0010-0285(70)90005-8

Winograd, E. \& Rivers-Bulkeley, N. T. (1977). Effects of changing context on remembering faces. Journal of Experimental Psychology: Human Learning and Memory, 3, 397-405. doi:10.1037/0278-7393.3.4.397 
Appendix $A$

Description Form

Gender

Age

Ethnicity

Please write down everything you can remember about the crime.

Please write down everything you can remember about both of the criminals (e.g., what did the person look like, what did she/he do, etc.) 


\section{Appendix $B$}

\section{Simultaneous Lineup Form}

Instructions: "Please look at the lineup photos. The criminal's picture may or may not be present. If you see the criminal please place a check mark in the box matching the criminal's lineup number. If you do not see the criminal please place a check mark in the box marked "Not Here."

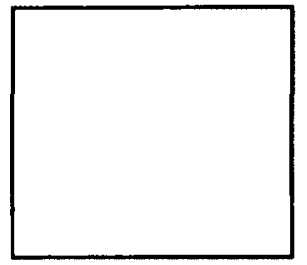

1

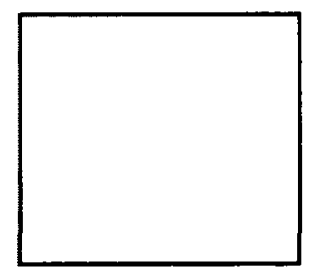

4

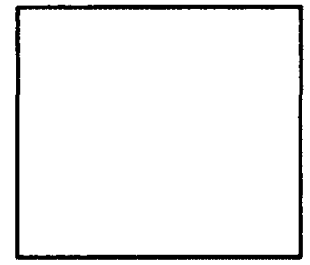

2

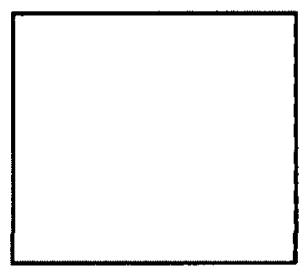

5

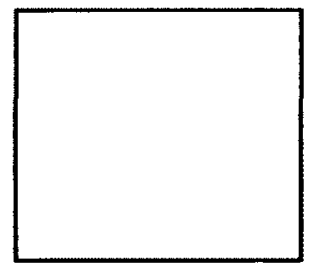

3

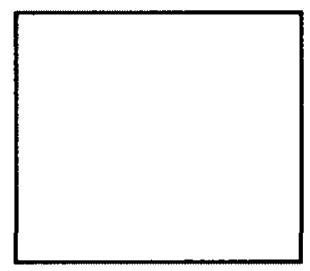

6

NOT HERE

If you selected someone please describe the role this person played in the crime.

How confident are you that you made the correct decision? Please rate your confidence level on a scale from 0 to 100 by circling the appropriate number.

$0 \ldots \ldots .10 \ldots \ldots . .20 \ldots \ldots .30 \ldots \ldots . . .40 \ldots \ldots 50 \ldots \ldots .60 \ldots \ldots .70 \ldots$

80.

Not Confident

Confident

Moderately

Confident

Absolutely 


\section{Appendix $C$}

\section{Deception Awareness Questionnaire}

1. Did you hear anything about the project before seeing the videotape? Please check the appropriate box.

\section{$\square$ YES \\ 口 NO}

If yes, what did you hear about the study?

2. Did you know anyone from the lineup?

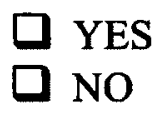

If yes, who did you know? 